Revista de Estudios Histórico-Jurídicos [Sección historia del pensamiento jurídico]

XLII (Valparaíso, Chile, 2020)

[pp. 691-720]

\title{
ANÁLISIS CRÍTICO DE LAS IMPLICANCIAS FILOSÓFICO- JURÍDICAS DE LAS NOCIONES DE ORDEN COSMOLÓGICO Y JUSTICIA CÓSMICA EN LA SENTENCIA DE ANAXIMANDRO DE Mileto
}

[Critical analysis of the philosophical-legal implications of the notions of cosmological order and cosmic justice in Anaximander's saying]

\author{
Gonzalo Agliati VÁsquez* \\ Pontificia Universidad Católica de Valparaíso, Chile**
}

\section{RESUMEN}

El presente artículo tiene por objeto analizar los aspectos principales de la sentencia de Anaximandro de Mileto, especialmente aquellos de índole filosófica y jurídica, a partir de los cuales es posible sostener que dicho filósofo griego reconoció la existencia de un orden cosmológico asimilable a ciertos principios fundamentales del Derecho Natural y sostuvo la validez de una noción particular de justicia cósmica, comprensiva de caracteres retributivos, restaurativos y distributivos, y cuya administración corresponde al tiempo, en tanto entidad trascendente en su inmanencia.

\section{Palabras clave}

Anaximandro de Mileto - filosofía griega - filosofía del derecho - derecho natural - justicia.

\section{Abstract}

The purpose of this paper is to analyze the main aspects of Anaximander of Miletus' sentence, especially those of a philosophical and legal nature, from which is possible to maintain that Greek philosopher recognized the existence of a cosmological order assimilable to certain fundamental principles of Natural Law and affirmed the validity of a particular notion of cosmic justice, which includes retributive, restorative and distributive characters, and whose administration belongs to time, as a transcendent entity in its immanence.

\section{KeY Words}

Anaximander of Miletus - Greek philosophy - Legal Philosophy - Natural Law - justice.

RECiBido el 27 de marzo de 2020 y ACEPTADO el 2 de julio de 2020

* Abogado. Licenciado en Ciencias Jurídicas por la Pontificia Universidad Católica de Valparaíso. Estudiante del Programa de Magíster en Filosofía de la Pontificia Universidad Católica de Valparaíso. Becario CONICYT-PFCHA/Magíster Nacional/2019-22190200. Profesor de Derecho Penal de la Pontificia Universidad Católica de Valparaíso. Correo electrónico: g.agliati@gmail.com.

**En memoria de Eliana del Carmen y Miguel Ángel, Mi abuela y mi padre, Eternos en lo ilimitado 


\section{INTRODUCCIÓN}

Los orígenes de la filosofía del derecho, según lo sostenido por W. Jaeger en las páginas iniciales de su opúsculo Alabanza de la ley, no deben circunscribirse a la dogmática moderna o contemporánea, sino que se remontarían a los postulados de los pensadores de la Antigua Grecia. Con todo, dicha afirmación no sólo comprende las formulaciones propuestas por Platón, Aristóteles y los demás exponentes de la filosofía peripatética-quienes, de forma similar a los autores contemporáneos, desarrollaron una reflexión abstracta y compleja sobre los conceptos jurídicos fundamentales y sus implicancias-, puesto que es posible identificar referencias a la naturaleza del derecho y de la justicia en la obra atribuida a los primeros filósofos griegos ${ }^{1}$.

Los estudiosos que suscriben esta tesis, dentro de los que destacan el autor anteriormente citado y A. Kaufmann ${ }^{2}$, advierten las primeras referencias de índole jurídica en la época arcaica, específicamente en los poemas de Homero y Hesíodo, sin embargo, coinciden en reconocer a Anaximandro de Mileto como el primer exponente de la reflexión filosófica relativa a los principios o instituciones del derecho.

El presente trabajo tiene por objeto fundamentar la atribución de dicho mérito a Anaximandro, para lo cual se expondrán y analizarán las principales premisas arrogadas al filósofo milesio, con especial énfasis en aquellas que puedan interpretarse desde una perspectiva vinculada con la filosofía del derecho.

En razón de lo anterior, se incluirán breves consideraciones en torno a las dificultades asociadas al estudio de los filósofos presocráticos o p r e p la tó n i c o s ${ }^{3}$ y a algunos aspectos de la vida y obra de Anaximandro de Mileto. Estos contenidos fungirán como antecedentes del análisis específico de las implicancias iusfilosóficas de la denominada "sentencia de Anaximandro", especialmente en lo relativo a las dinámicas cosmológicas y a su noción particular de justicia.

${ }^{1}$ JAEGER, Werner, Alabanza de la ley. Los orígenes de la Filosofía del Derecho y los griegos (2a ed., 1947, trad. cast. Madrid, Centro de Estudios Constitucionales, 1982), pp. 2-4.

${ }^{2}$ En términos generales, las referencias sucesivas a la obra de dicho filósofo se limitarán a Kaufmann, Arthur, Panorámica histórica de los problemas de la filosofia del derecho, en KaUfmann, Arthur; Hassemer, Winfried; Robles Morchón, Gregorio (a cura di), El pensamiento jurídico contemporáneo, (Madrid, Editorial Debate, 1992), pp. 47-141.

${ }^{3}$ La primera de las denominaciones señaladas es empleada con mayor frecuencia por los autores abocados al estudio de dichos filósofos y sus postulados. Entre quienes prefieren la categoría de fil ó s of os p r e pla tó n i c o s se destaca F. Nietzsche, para quien esta elección se fundamenta en que "Platón es el primer gran carácter mixto, tanto por su filosofía como por el tipo filosófico que encarna [...] no se puede decir que sea una concepción original [...] En cambio, esa serie de presocráticos representan tipos puros y no mezclados, tanto por sus filosofemas como por su carácter. Sócrates es el último de esta serie. Todos ellos pueden ser llamados, si se quiere, los «exclusivos»". Vid. NiETzSCHe, Friedrich, Los filósofos preplatónicos (1913, trad. cast. Madrid, Editorial Trotta, 2003), pp. 19-20. En lo sucesivo de este artículo se preferirá la denominación def i l ó s o f o s p r e s o c rát i c o s por corresponder a aquella de uso más extendido en la literatura especializada. 


\section{CONSIDERACiONES PRELIMINARES}

La filosofía antigua, particularmente aquella desarrollada en Grecia entre los siglos VII y IV a.C. constituye una de las etapas fundamentales en la progresión histórica de esta disciplina, por lo que su estudio resulta de una importancia indiscutible para el tratamiento de cualquier asunto de índole filosófica. A pesar de que esta aseveración resulta predicable respecto del pensamiento helénico en general, adquiere especial énfasis respecto de los filósofos asociados a la tradición jónica, específicamente aquellos originarios de Mileto, colonia griega emplazada en el territorio de Asia Menor.

De forma generalizada se considera a dichos pensadores como los primeros exponentes de lafilos ofía de la naturaleza, en tanto se consagraron al análisis y formulación de consideraciones racionales en torno al universo y sus elementos constitutivos ${ }^{4}$. Aun cuando no es posible descartar categóricamente la existencia de otros autores adscritos a dicha tradición, sus principales exponentes corresponden a Tales, Anaximandro y Anaxágoras, quienes, según algunos comentaristas, habrían integrado la denominada Escuela de Mileto5. Sin perjuicio de que el examen analítico propuesto se limitará al segundo de los filósofos mencionados, resulta necesario exponer algunas cuestiones generales vinculadas con las dificultades inherentes al estudio de dichos pensadores y con ciertos aspectos biográficos de Anaximandro.

\section{Principales dificultades asociadas al estudio de los primeros filósofos griegos}

En términos generales, es posible sostener que, desde una perspectiva contemporánea, la elaboración de propuestas analíticas, expositivas e interpretativas referidas a los postulados de los primeros filósofos griegos, particularmente a aquellos que se atribuyen a los pensadores milesios, debe lidiar con una serie de

${ }^{4}$ Entre otros, véase Bernabé, Alberto, Fragmentos presocráticos. De Tales a Demócrito (3a ed., Madrid, Alianza Editorial, 2008), p. 17; GuTHRIE, William, Los filósofos griegos. De Tales a Aristóteles (2a ed., 7a reimp., 1950, trad. cast. Méjico D.F., Fondo de Cultura Económica, 2010), p. 24; JAEGER, Werner, La teología de los primeros filósofos griegos (1947, trad. cast. Méjico D.F., Fondo de Cultura Económica, 1952), pp. 24-27 y JAEGER, Werner, Paideia: los ideales de la cultura griega (2a ed., 22a reimp., 1933-1945, trad. cast. Méjico D.F., Fondo de Cultura Económica, 2011), pp. 150-156. El primero de los autores citados expone brevemente las condiciones culturales, económicas, políticas y sociales de Mileto que posibilitaron el surgimiento de esta clase de pensamiento filosófico. En un sentido similar, KAHN, Charles, Anaximander and the Origins of Greek Cosmology (New York, Columbia University Press, 1960), pp. 199-215 y SEAFORD, Richard, Money and the Early Greek Mind. Homer, Philosophy, Tragedy (Cambridge, Cambridge University Press, 2004), pp. 199-201. Este último autor enfatiza en el rol desempeñado por los factores económicos en el apogeo de la filosofía milesia.

${ }^{5}$ Así, GuTHRIE, William, cit. (n. 4), p. 32, quien fundamenta su afirmación en las sucesivas relaciones de maestro y discípulo que habrían existido entre dichos filósofos. Si bien no corresponde a la cuestión central de este artículo, considero pertinente advertir que la posibilidad de establecer escuelas filosóficas integradas por pensadores de los siglos VII y VI a.C. corresponde a un anacronismo, puesto que dicha categoría sólo resulta aplicable a partir de la tradición socrática-platónica. En el mismo sentido, desestiman la existencia de la Escuela antes señalada, JAEger, Werner, Paideia, cit. (n. 4), pp. 155-156 y Nietzsche, Friedrich, cit. (n. 3), pp. 47-48. 
contratiempos y dificultades atribuibles a causas diversas ${ }^{6}$. La mayoría de dichas circunstancias adversas se derivan como consecuencia de la considerable lejanía temporal que media entre el investigador y su objeto de reflexión. Más de dos mil quinientos años, aproximadamente, se interponen entre los filósofos del siglo VI a.C. y los análisis académicos formulados en el siglo XXI.

Las diferencias contextuales, en especial aquellas de índole social y cultural, inciden directamente en la formulación de hipótesis interpretativas, las cuales suelen adquirir un carácter especulativo o estructurarse a partir de la aplicación de categorías, instituciones y criterios previstos en la obra filosófica del exégeta o en la de sus contemporáneos ${ }^{7}$. Esta particularidad propende necesariamente en una tergiversación y distorsión de los postulados originales sometidos a escrutinio.

No obstante lo anterior, estas consideraciones no son predicables exclusivamente de las interpretaciones actuales, sino que es posible advertirlas en los comentarios atribuidos a pensadores griegos posteriores a la tradición jónica. A modo de ejemplo, la doxografía de Aristóteles y sus discípulos, sin perjuicio de sus indiscutibles méritos, adolece de un defecto importante, consistente en la aplicación de conceptos y categorías filosóficas propias a la doctrina de sus predecesores. Dicho tratamiento se fundamentaría en "su consideración de la filosofía precedente como un titubeante progreso hacia la verdad que él mismo [Aristóteles]

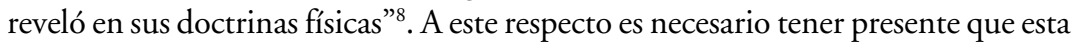
caracterización de los cometarios platónicos, aristotélicos y de los demás autores peripatéticos no sólo se sustenta en una actitud intelectual particular, sino que también se explica en función del prolongado lapso temporal que existe entre los inicios de la filosofía griega y dichos ejercicios doxográficos, los cuales han sido datados, mayoritariamente, a partir del siglo IV a.C. ${ }^{9}$

${ }^{6}$ Para una breve referencia a las problemáticas asociadas al estudio de los primeros filósofos jónicos, véase KaHN, Charles, cit. (n. 4), p. 11.

${ }^{7}$ Esta circunstancia ha sido advertida por M. Heidegger en los pasajes iniciales de su estudio dedicado a la sentencia de Anaximandro, en razón de lo cual adopta como premisa una exhortación a "pensar griegamente el pensar de los griegos". Vid. HeIdEgGer, Martin, La sentencia de Anaximandro (1946), ahora, en ÉL MISMO, Caminos de bosque (1984, trad. cast. Madrid, Alianza Editorial, 2010), pp. 249-250. Con todo, como se advertirá en acápites sucesivos de este artículo, dicho filósofo no consigue satisfacer plenamente esta pretensión, introduciendo categorías propias de su pensamiento y aplicando consideraciones anacrónicas respecto del filósofo milesio.

${ }^{8}$ Cfr. KirK, Geoffrey; Raven, John; SCHOFIELd, Malcolm, Los flósofos presocráticos. Historia crítica con selección de textos (2a ed., 2a reimp., 1983, trad. cast. Madrid, Editorial Gredos, 1987), pp. 18-22. Además del fragmento transcrito, los autores citados analizan brevemente la influencia de los comentarios aristotélicos en la obra de Teofrasto y la de esta última en la doxografía posterior. En un sentido similar, véase, entre otros, BERnABÉ, Alberto, cit. (n. 4), p. 37.

${ }^{9}$ Resulta interesante lo sostenido por KIRK, Geoffrey; Raven, John; Schofield, Malcolm, cit. (n. 8), pp. 15-16, quienes advierten mayor fidelidad en las citas recopiladas en la obra de Simplicio, filósofo neoplatónico del siglo VI d.C., que en la de Platón y Aristóteles (siglos V y IV a.C.), toda vez que estos últimos reunieron escasos fragmentos directos, combinándolos con paráfrasis y comentarios críticos. Estas consideraciones permiten advertir un supuesto en que la distorsión en comentario se ve determina en mayor medida por la actitud intelectual del comentarista que por la distancia temporal que media entre este y su objeto de análisis. 
Una segunda dificultad asociada al estudio de los filósofos presocráticos corresponde a la inexistencia de registros escritos de sus postulados o, en caso contrario, al reducido número de fragmentos directos que han podido conservarse de estos. Con respecto a los pensadores de Mileto, según señala A. Bernabé en los pasajes introductorios de su monografía Fragmentos presocráticos, Tales no habría legado obra escrita alguna, mientras que de Anaximandro y Anaxímenes sólo se cuenta con una reducida cantidad de extractos que les han sido atribuidos de forma presunta ${ }^{10}$.

Dicha circunstancia, vinculada con la tradición oral que caracteriza a la poesía griega de la época arcaica, incide directamente en la relevancia que debe atribuirse a los comentarios y obras doxográficas relativas a los primeros filósofos griegos ${ }^{11} \mathrm{y}$, consecuencialmente, en la ocurrencia de los problemas expuestos en los párrafos precedentes ${ }^{12}$.

Junto con lo anterior, el estudio de la filosofía antigua, específicamente aquella desarrollada con anterioridad al siglo $\mathrm{V}$ a.C., requiere de una serie de conocimientos especializados, los cuales no se circunscriben a dicha disciplina, sino que se extienden a otras áreas del conocimiento, como por ejemplo, la filología y la etimología ${ }^{13}$. Esta particularidad determina de forma considerable el trabajo realizado por aquellos estudiosos que no cuentan directamente con formación en dichas áreas, puesto que deben acceder a los textos respectivos mediante traducciones, las cuales suelen alterar su sentido original en virtud de la introducción de paráfrasis y de consideraciones interpretativas ${ }^{14}$.

Con todo, las dificultades antedichas no deben entenderse como un desincentivo al desarrollo de estudios analíticos en esta materia, sino que imponen la necesidad de asumir ciertas limitaciones inherentes a dicha actividad académica y de considerar de forma cautelosa y pormenorizada las fuentes directas e indirectas disponibles. La adopción de la actitud intelectual propuesta en este acápite hace posible la elaboración de propuestas significativas en el tratamiento de las principales cuestiones filosóficas abordadas por los pensadores presocráticos.

${ }^{10}$ Véase Bernabé, Alberto, cit. (n. 4), p. 28. Adicionalmente a lo ya señalado, el autor citado sostiene que, desde una perspectiva estilística, los fragmentos atribuidos a Anaximandro y Anaxímenes se vinculan, respectivamente, con la tradición poética y las obras de naturaleza logográfica.

${ }^{11}$ Para una exposición general del sistema de fuentes disponible en esta materia, véase la nota introductoria contenida en KIRK, Geoffrey; RAVEN, John; SCHOFIELD, Malcolm, cit. (n. 8), pp. 15-23.

${ }^{12}$ Así, KAHN, Charles, cit. (n. 4), pp. 11-12, identifica este aspecto como una característica esencial en el estudio de los filósofos milesios del siglo VI a.C. En términos similares, NiETzSCHE, Friedrich, cit. (n. 3), pp. 20-21, se lamenta de la "auténtica desgracia [de] que nos quede tan poco de estos filósofos originales", ya que implica que su análisis y comprensión se restrinjan excesivamente.

${ }^{13}$ En este sentido, BERnABÉ, Alberto, cit. (n. 4), pp. 33-37, quien, además de las dificultades lexicográficas, señala aquellas asociadas a la complejidad intrínseca de los términos filosóficos y a la transmisión fragmentaria de las doctrinas de los presocráticos.

${ }^{14}$ A este respecto, véase Ávila VÁsquez, Manuel, En torno a la sentencia de Anaximandro. Dos interpretaciones o sobre la justicia y la reparación, en Universitas Philosophica, 28 (enero-junio 2011), 56, p. 64, quien sostiene que el estudio de los presocráticos "sólo lo podemos llevar a cabo con los ojos del moderno" y que "toda traducción [...] es ya una interpretación”. 


\section{Aspectos generales de la vida y obra de Anaximandro de Mileto}

No existe consenso entre los autores en torno a los datos biográficos de Anaximandro. Si bien se admiten ampliamente algunos de sus antecedentes $-v$. gr. su origen milesio y su participación en algunas campañas colonizadoras ${ }^{15}$-, la discusión se extiende a ciertos aspectos esenciales de su existencia, como por ejemplo, las fechas de su nacimiento y deceso.

A este respecto, la mayoría de sus comentaristas -clásicos y contemporáneosseñalan a la Olimpiada 58 (547-546 a.C.) como hito de referencia, sin embargo, las estimaciones realizadas a partir de ésta resultan divergentes, ya que algunos autores sostienen que habría tenido cuarenta años de edad al momento de celebrarse dicho evento ${ }^{16}$, mientras que otros le atribuyen veinticuatro años por sobre dicho cómputo ${ }^{17}$. Asimismo, ciertos estudiosos han datado el fallecimiento de Anaximandro poco después de la Olimpiada antes señalada ${ }^{18}$.

Un segundo aspecto controvertido entre los doxógrafos corresponde a la relación que habría existido entre Tales y Anaximandro. Dicho vínculo ha sido descrito a partir de diversas perspectivas -amigos, compañeros, conciudadanos, parientes-, sin embargo, la discusión suele concentrarse en la factibilidad de establecer una sucesión entre el pensamiento de ambos filósofos, a partir de una dinámica de maestro y discípulo.

Aun cuando algunas opiniones basadas en las expresiones utilizadas en los testimonios clásicos aseveran que Anaximandro habría estudiado directamente con Tales ${ }^{19}$, resulta más apropiada la posición adoptada por G. Kirk, J. Raven y M. Schofield, quienes afirman que sólo es posible advertir que ambos filósofos "procedían de la misma ciudad y que uno era algo más joven que el otro" ${ }^{20}$.

${ }^{15}$ Refieren expresamente el hecho de que Anaximandro habría encabezado la expedición de colonización de Apolonia, entre otros, Bernabé, Alberto, cit. (n. 4), p. 50 y Nietzsche, Friedrich, cit. (n. 3), p. 46.

${ }^{16}$ Cfr. Kirk, Geoffrey; Raven, John; Schofield, Malcolm, cit. (n. 8), p. 154. Dichos autores sostienen que Teofrasto, en su obra Opiniones de los físicos, habría realizado una afirmación semejante a este respecto.

${ }^{17}$ Entre otros, NiETZSCHE, Friedrich, cit. (n. 3), p. 46, sustenta su estimación en lo que habría afirmado Apolodoro, cuya obra habría sido citada a este respecto en los escritos doxográficos de Diógenes Laercio. Sin perjuicio de no afirmarlo expresamente, la consignación de ciertos datos y fechas permite sostener que GIANNINI, Humberto, Esbozo para una historia de la filosofía (3a ed., Santiago, Editorial Dionysos, 1979), p. 15, adhiere a esta posición.

${ }^{18}$ Así, Giannini, Humberto, cit. (n. 17), p. 15, quien estima que la muerte de Anaximandro habría ocurrido el año 547 a.C. En contrapartida, este autor señala el año 610 a.C. como fecha de nacimiento del milesio, a partir de lo cual es posible fundamentar la deducción consignada en la nota precedente. Parece pronunciarse en el mismo sentido, HeIdegGer, Martin, La sentencia, cit. (n. 7), p. 239. Se oponen a lo anterior, Kirk, Geoffrey; RAVEN, John; Schofield, Malcolm, cit. (n. 8), pp. 154-155, quienes estiman dichas afirmaciones como erróneas.

${ }^{19}$ A modo de ejemplo, véase Giannini, Humberto, cit. (n. 17), p. 15 y GuThrie, William, cit. (n. 4), p. 32. En lo relativo a esta posición, debe tenerse presente lo señalado precedentemente en la nota al pie $\mathrm{N}^{\circ} 5$.

${ }^{20}$ Kirk, Geoffrey; Raven, John; Schofield, Malcolm, cit. (n. 8), p. 155. En un sentido similar, KAHN, Charles, cit. (n. 4), pp. 28-29 y NiETZSCHE, Friedrich, cit. (n. 3), pp. 47-48, sosteniendo el primero de ellos que el análisis de las expresiones utilizadas por los comentaristas clásicos sólo permitiría identificar "un contacto personal entre un hombre joven y otro mayor". 
Sin perjuicio de las discusiones antes señaladas, es posible identificar algunos aspectos fundamentales de los postulados atribuidos a Anaximandro.

En primer término, como ocurre con la mayoría de los primeros filósofos griegos, una de las cuestiones centrales en la obra del pensador milesio consiste en el análisis y reflexión generalizados en torno al orden natural del cosmos y al principio $\left(\dot{\alpha} \varrho \chi \eta^{21}\right)$ que lo informa. Esta descripción fundamenta el empleo de la categoría фvбıкoí ("naturalistas" o "filósofos de la naturaleza”) para designar a dichos autores.

En segundo término, las formulaciones teóricas de Anaximandro dan cuenta de una mayor complejidad -estilística y conceptual-y madurez intelectual respecto de las de su antecesor, Tales de Mileto ${ }^{22}$, toda vez que, como se advertirá en los acápites subsecuentes, sus explicaciones trascendieron de la realidad física sensible, alcanzando un mayor nivel de abstracción. Estas características inciden de forma decisiva en la influencia que ejerció su pensamiento en diversos filósofos posteriores.

En último término, es necesario tener presente que parte importante de los comentaristas y doxógrafos de Anaximandro no se limitan a considerarlo como una figura innovadora en los orígenes del pensamiento occidental a partir de lo ya señalado, sino que, adicionalmente, destacan la considerable cantidad de temáticas abordadas en su quehacer científico ${ }^{23}$ y le atribuyen la autoría de la primera obra filosófica escrita.

En efecto, Anaximandro habría redactado un tratado en prosa ${ }^{24}$ titulado Sobre

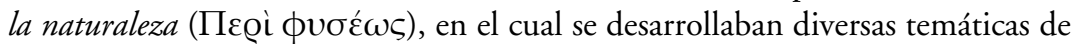
índole cosmológica, antropológica y otras similares ${ }^{25}$. Dentro de los contenidos

${ }^{21}$ Algunos comentaristas de la obra de Anaximandro han sostenido que debe ser considerado

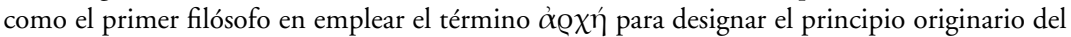
cosmos, sin embargo, no existe consenso en torno a dicha afirmación. Las principales posiciones implicadas en esta discusión consisten en la desestimación del uso de dicha expresión por parte de Anaximandro -reputándose como una incorporación atribuible a Teofrasto o a algún comentarista posterior- y al reconocimiento de su empleo por parte del filósofo milesio, ya sea en un sentido común o técnico. A este respecto, véase KaHN, Charles, cit. (n. 4), pp. 29-32; KirK, Geoffrey; Raven, John; Schofield, Malcolm, cit. (n. 8), pp. 164-165; JaEger, Werner, La teología, cit. (n. 4), pp. 31-34 y NiETZSCHE, Friedrich, cit. (n. 3), p. 48.

${ }^{22}$ Entre otros, Giannini, Humberto, cit. (n. 17), p. 15; Guthrie, William, cit. (n. 4), p. 35; Jaeger, Werner, Paideia, cit. (n. 4), pp. 156-158 y Nietzsche, Friedrich, cit. (n. 3), pp. 48-49. Con todo, este último autor considera que, salvo en lo relativo a la identificación del principio informador del cosmos, las ideas físicas de Anaximandro corresponden a una mera continuación de los postulados de Tales.

${ }^{23} \mathrm{La}$ actividad científica de Anaximandro no se limitó al plano teórico, puesto que habría introducido a Mileto ciertos instrumentos métricos de origen babilonio y diseñado el primer mapa de la superficie terrestre conocida. En este punto, véase, entre otros, BERnABÉ, Alberto, cit. (n. 4), p. 50; Jaeger, Werner; Paideia, cit. (n. 4), pp. 156-157; Kirk, Geoffrey; Raven, John; Schofield, Malcolm, cit. (n. 8), pp. 157-160 y NieTzSche, Friedrich, cit. (n. 3), p. 47.

${ }^{24}$ En este sentido, KAHN, Charles, cit. (n. 4), p. 240, sostiene esta afirmación, en desmedro de aquellas interpretaciones que atribuyen dicha innovación a otros autores.

${ }^{25}$ Para una breve exposición de las características que han sido atribuidas a dicha obra, véase KaHn, Charles, cit. (n. 4), p. 6; KIRK, Geoffrey; Raven, John; SCHOfield, Malcolm, cit. (n. 8), pp. 156-157 y NietzsCHe, Friedrich, cit. (n. 3), pp. 47-48. Este último autor controvierte la 
particulares que habrían sido abordados en dicha obra se destacan la descripción detallada de la configuración y orden interno del cosmos -incluyendo referencias a la forma y organización de la tierra, la disposición de los astros que la circundan y la ocurrencia de ciertos fenómenos meteorológicos- y un esbozo de una teoría evolutiva de los organismos vivientes ${ }^{26}$.

Sin perjuicio de la discusión existente en torno a la veracidad del título asignado al tratado ${ }^{27}$ y de la ausencia de fragmentos directos que se hubiesen conservado del mismo - toda vez que el escrito original se reputa como extraviado-, la mayoría de las opiniones expertas admiten su existencia y el hecho de que habría sido examinado de primera fuente por Aristóteles y Teofrasto ${ }^{28}$. A partir de los comentarios elaborados por estos últimos autores ha sido posible acceder posteriormente a ciertos pasajes de la doctrina filosófica de Anaximandro ${ }^{29}$.

\section{ANÁlisis E INTERPRETACión DE LA SENTENCIA DE ANAXimandro}

El único fragmento íntegro que ha sido adjudicado, al menos de forma presunta, a Anaximandro ${ }^{30}$-calificado por M. Heidegger como "la sentencia más antigua del pensamiento occidental" ${ }^{-}$-, habría sido recogido por Teofrasto en

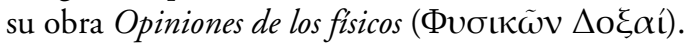

veracidad del testimonio legado por Suidas, en el cual se mencionan otras obras escritas cuya autoría le correspondería a Anaximandro.

${ }^{26}$ BERNABÉ, Alberto, cit. (n. 4), pp. 54-55 ofrece una descripción detallada de las temáticas presumiblemente abordadas por Anaximandro. Asimismo, GianNinI, Humberto, cit. (n. 17), p. 15, incluye una somera referencia a ciertas cuestiones de índole cosmológico.

${ }^{27}$ A este respecto, KAHN, Charles, cit. (n. 4), p. 6, nota $\mathrm{N}^{\circ}$ 2, señala que dicho título fue asignado alternativamente a diversas obras adjudicadas a diferentes filósofos presocráticos, en razón de la taxonomía que Aristóteles propuso aplicar a estos. Esta afirmación ha sido citada, entre otros, por KIRK, Geoffrey; RAVEN, John; SCHOfield, Malcolm, cit. (n. 8), p. 156.

${ }^{28}$ Cfr. Bernabé, Alberto, cit. (n. 4), pp. 50-51; Guthrie, William, cit. (n. 4), p. 35; Kahn, Charles, cit. (n. 4), pp. 6-7 y KirK, Geoffrey; Raven, John; Schofield, Malcolm, cit. (n. 8), p. 156.

${ }^{29}$ La tradición doxográfica clásica en torno a Anaximandro no se circunscribe exclusivamente a dichos autores, toda vez que se han identificado fragmentos correspondientes, entre otros, a Simplicio, Pseudo-Plutarco, Aecio e Hipólito. Sin perjuicio de que las opiniones de algunos de dichos intérpretes serán aludidas en este artículo, es necesario advertir que éstas suelen articularse a partir de lo referido por Aristóteles y Teofrasto. A este respecto, véase KAHN, Charles, cit. (n. 4), pp. 11-24.

${ }^{30}$ No obstante la admisión generalizada de esta afirmación entre los comentaristas, BERNABÉ, Alberto, cit. (n. 4), p. 56, consigna una serie de fragmentos de Anaximandro en los que señala características predicables del principio cosmológico que identificó en su teoría. Sin perjuicio de la eventual veracidad de dichos pasajes, es preciso advertir que corresponden a afirmaciones disgregadas que no permiten reconstruir la doctrina del filósofo milesio.

${ }^{31}$ Véase HeidegGer, Martin, La sentencia, cit. (n. 7), p. 239. Entre los autores que adhieren a la caracterización heideggeriana, véase Oppermann, Jan, Anaximander's Rhythm and the Question of Justice, en Law and Critique, 14 (2003), 1, pp. 45-47. Este último autor, además de considerar a la sentencia de Anaximandro como el "fragmento más antiguo de la filosofía occidental", destaca su originalidad, en tanto característica que trascendería hasta las etapas de desarrollo contemporáneo de dicha disciplina. 
Lamentablemente, este último texto, al igual que el tratado atribuido a Anaximandro, no se ha conservado hasta nuestros días, por lo que resulta imposible analizar directamente los comentarios y observaciones de dicho autor. No obstante, Simplicio, filósofo neoplatónico ampliamente reconocido por su labor exegética referida a los presocráticos, incluyó en su Comentario sobre la Física de Aristóteles $(24,13)$ una cita del comentario de Teofrasto, a partir de la cual ha sido posible acceder a la sentencia del pensador milesio y a otros aspectos de su doctrina ${ }^{32}$.

De acuerdo con la versión más ampliamente admitida, el texto griego de

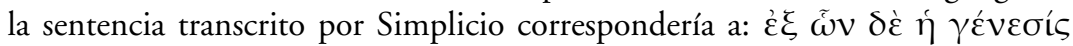

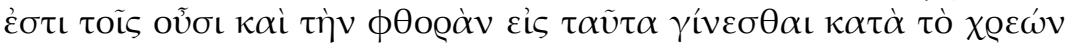

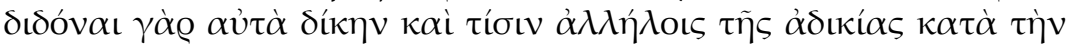

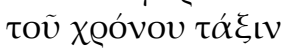

A pesar de existir diversas traducciones de este fragmento -algunas de las cuales serán referidas en los acápites posteriores de este artículo-, A. Bernabé ha propuesto una aproximación que parece dar cuenta de forma más adecuada del sentido original atribuible a la sentencia. Dicha traducción ha sido formulada en los siguientes términos: "Las cosas perecen en lo mismo que les dio el ser, según la necesidad. Y es que se dan mutuamente justa retribución por su injusticia, según la disposición del tiempo"33.

Aun cuando el texto de la sentencia de Anaximandro se limita a lo transcrito, el comentario de Simplicio se extiende a otros aspectos de su doctrina, específicamente, a aquellos relativos al principio originario del cosmos y a la forma en que surgen y se organizan los elementos constitutivos del mundo ${ }^{34}$. Los pasajes adicionales de dicho texto serán abordados en los apartados pertinentes de la presente investigación.

Junto con lo anterior, desde una perspectiva formal, el doxógrafo neoplatónico sostiene, a partir de los comentarios de Teofrasto, que el filósofo milesio se expresa en "términos más propios de la poesía" ${ }^{2}$. Dicha calificación evidencia la utilización de un lenguaje metafórico o figurativo, el cual habría sido empleado por Anaximandro, presumiblemente, como recurso literario, con el objeto de reforzar el sentido y la originalidad de sus planteamientos. Con todo, es preciso considerar la crítica formulada por W. Jaeger a la afirmación de Simplicio, toda vez que, además de adolecer de una serie de imprecisiones respecto de la sentencia, "menoscaba la fuerza de su lenguaje explicando lo que tiene de gráfico como pura metáfora" 36 .

${ }^{32}$ A este respecto, KaHN, Charles, cit. (n. 4), p. 35, sostiene que no existen motivos para considerar que Simplicio haya alterado la cita original de Teofrasto.

${ }^{33}$ Bernabé, Alberto, cit. (n. 4), p. 56. Salvo mención en contrario, las sucesivas referencias al fragmento de Anaximandro deben entenderse hechas respecto de esta versión.

${ }^{34}$ La estructura del texto de Simplicio permite distinguir entre los pasajes de su autoría comentarios y paráfrasis del filósofo milesio-y aquellos directamente atribuibles a Anaximandro. Esta afirmación puede comprobarse a partir de la lectura de la traducción realizada por BERNABÉ, Alberto, cit. (n. 4), p. 56.

${ }^{35}$ Afirman la adopción de dicho comentario a partir del texto de Teofrasto, entre otros, KAHN, Charles, cit. (n. 4), p. 35 y KirK, Geoffrey; Raven, John; SCHOfIeld, Malcolm, cit. (n. 8), p. 178.

${ }^{36}$ JAEGER, Werner, La teología, cit. (n. 4), p. 40. 
Sin perjuicio de lo ya señalado, la admisión del carácter metafórico de las expresiones previstas en el fragmento no debe entenderse, necesariamente, como un menoscabo al sentido expresivo de este, en especial si se tiene presente la interpretación propuesta en los pasajes centrales del párrafo precedente.

En relación con otras consideraciones de índole formal, resulta llamativo que la sentencia, a pesar de su reducida extensión, sintetice múltiples aspectos de la doctrina del filósofo de Mileto. Esta afirmación resulta compatible con aquellas interpretaciones que sostienen que el texto original del fragmento sólo correspondería a algunas de las secciones previstas en la transcripción de Simplicio ${ }^{37}$. A pesar de las discrepancias que podrían surgir a este respecto, el análisis que se desarrollará en lo sucesivo comprenderá la totalidad del texto citado por el comentarista, tanto en lo atribuible directamente a Anaximandro como en lo relativo a algunos de los apartados que han sido señalados como complementos doxográficos ${ }^{38}$.

En términos generales, las alusiones a la doctrina de Anaximandro previstas en la obra de Simplicio admiten sistematizarse en función de tres unidades temáticas, las cuales corresponden a la identificación de "lo ilimitado" como principio cosmogónico, las implicancias derivadas de la "teoría de los opuestos” y la noción de justicia cósmica. Los apartados sucesivos del presente estudio se limitarán a los últimos dos tópicos señalados, ya que estos revisten mayor significación desde la perspectiva del análisis jurídico ${ }^{39}$.

\section{Alcances cosmológicos y jurídicos de la Teoría de los Opuestos}

La idea de oposición y los vínculos de tensión y contrariedad existentes entre los diversos elementos que componen el universo corresponden a algunos de los presupuestos esenciales de la filosofía de Anaximandro de Mileto. Sin embargo, para su adecuado entendimiento resulta indispensable tener presente ciertas consi-

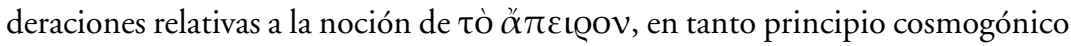
identificado por dicho filósofo.

En concepto del pensador milesio, el origen del mundo y de todo cuanto existe en él ${ }^{40}$ puede reconducirse, en último término, a cierta entidad informe,

${ }^{37}$ Entre otros, véase Engmann, Joyce, Cosmic Justice in Anaximander, en Phronesis, 36/1 (1991), pp. 2-3; HeIdegger, Martin, La sentencia, cit. (n. 7), pp. 252-253 y KiRK, Geoffrey; RAVEN, John; Schofield, Malcolm, cit. (n. 8), pp. 178-179. En términos generales, quienes

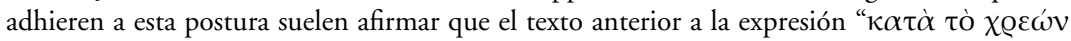
[...]" fue agregado por Teofrasto o Simplicio.

${ }^{38}$ Las referencias a la filosofía de Anaximandro en el comentario de Simplicio no se restringen al fragmento anteriormente citado, toda vez que en los pasajes iniciales de Física 24.13 se incluye una alusión expresa a "lo ilimitado" ( $\tau$ ò ă $\tau \varepsilon \iota \varrho O V)$, en tanto principio originario del cosmos, y a algunas de las características predicables de este.

${ }^{39}$ Es necesario tener presente que la exclusión del análisis pormenorizado del sentido, alcance y relevancia teórica de la noción de "lo ilimitado" sólo obedece a la razón señalada, toda vez que corresponde a un aspecto trascendental en la doctrina naturalista de Anaximandro, específicamente en lo relativo a los procesos cosmogónicos.

${ }^{40}$ A este respecto, Heidegger, Martin, La sentencia, cit. (n. 7), p. 246, agrupa todas las cosas que existen en el mundo - dioses, elementos de la naturaleza, hombres y sus creaciones- en torno a la expresión griega $\tau \dot{\alpha}$ óv $\tau \alpha$, la cual traduce como "lo ente múltiple en su totalidad". Para una exposición más precisa de la interpretación propuesta por este autor, véase HEIDEGGER, Martin, 
carente de distinciones internas, sin elementos diferenciables que la compongan y que, por lo tanto, está constituida por cierta clase de materia que no puede equipararse con ninguna de las cualidades o sustancias conocidas por el hombre. Dicha esencia primigenia corresponde a "lo ilimitado" ${ }^{41}$, entendido en un sentido temporal y espacial interno ${ }^{42}$.

Asimismo, algunos de los principales comentaristas de Anaximandro -v.gr. Aristóteles (Física 203b) e Hipólito (Refutación de todas las herejías 1, 6, 1) - enuncian otras características esenciales de lo ilimitado. A este respecto, dichos exégetas señalan que el óx $\varepsilon\llcorner\varrho o v$ es eterno, inmortal e indestructible, no envejece y gobierna y abarca todas las cosas ${ }^{43}$. La conjunción de dichas cualidades permite predicar una $\mathrm{n}$ a $\mathrm{t}$ r r l e za divin a respecto de lo ilimitado ${ }^{44}$, en tanto dirige y ejerce un influjo sobre todas las cosas que se reputan existentes.

Los entes surgidos desde lo ilimitado y, más específicamente, la materia que los compone, retornan a él una vez que perecen, completando el ciclo inherente a su existencia. Dicha dinámica de carácter periódico corresponde al d e v e n i r , en virtud del cual, la totalidad de las cosas cuenta con un instante preciso de nacimiento y de destrucción.

El sometimiento a los preceptos del devenir corresponde a una condición ineludible, predicable de todas las cosas, respecto de la cual sólo puede sustraerse el $\not ̋ \pi \varepsilon$ ŁOV, puesto que su naturaleza divina y la ausencia de límites espaciales y temporales -en los términos anteriormente señalados-, implican reconocerlo como una sustancia respecto de la cual no puede identificarse un momento de

The Beginning of Western Philosophy. Interpretation of Anaximander and Parmenides (2012, trad. ingl. Indiana, Indiana University Press, 2015), pp. 3-5.

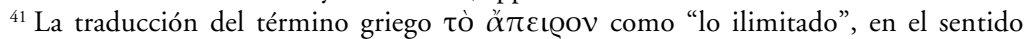
propuesto en el texto principal, resulta preferible a "lo infinito" (perspectiva espacial externa), toda vez que esta última noción es propia de la filosofía desarrollada con posterioridad a la de Anaximandro. Apuntan estas consideraciones, entre otros, Bernabé, Alberto, cit. (n. 4), p. 51; Nietzsche, Friedrich, cit. (n. 3), p. 52 y Kirk, Geoffrey; Raven, John; Schofield, Malcolm, cit. (n. 8), pp. 166-167. Los últimos autores citados señalan que el concepto de infinito habría sido aprehendido a partir de los planteamientos de Meliso y Zenón. Las objeciones formuladas a este respecto hacen criticable la denominación adoptada por ENGMANN, Joyce, cit. (n. 37), pp. 1-25, quien, a pesar de señalar alternativas más precisas, se refiere al principio de Anaximandro como "lo infinito".

${ }^{42}$ En este sentido, BernabÉ, Alberto, cit. (n. 4), p. 51; Giannini, Humberto, cit. (n. 17), p. 15; Guthrie, William, cit. (n. 4), p. 36; Jaeger, Werner, Paideia, cit. (n. 4), p. 158; Kahn, Charles, cit. (n. 4), pp. 232-233; KiRK, Geoffrey; RAven, John; Schofield, Malcolm, cit. (n. 8), pp. 165-167 y SEAFORD, Richard, cit. (n. 4), pp. 192-193. Una perspectiva similar corresponde a la sostenida por NIETZSCHE, Friedrich, cit. (n. 3), pp. 50-52, quien analiza la n a t u r a l e z a

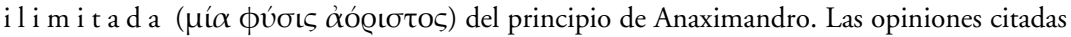
presuponen el rechazo de una de las interpretaciones aristotélicas, en la cual se afirma que el ă $\pi \varepsilon\llcorner$ LO $v$ corresponde a una sustancia intermedia o mezcla de los elementos tradicionalmente reconocidos.

${ }^{43}$ Véase la traducción de los fragmentos citados a este respecto en Bernabé, Alberto, cit. (n. 4), pp. 57-58.

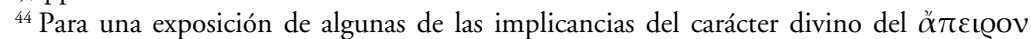
véase, entre otros, KIRK, Geoffrey; Raven, John; SCHOfield, Malcolm, cit. (n. 8), pp. 176-177. 
surgimiento y, en consecuencia, tampoco uno de perecimiento ${ }^{45}$, es decir, corresponde a una entidad carente de principio originario ${ }^{46}$.

A modo de síntesis, la cosmogonía de Anaximandro reconoce a lo ilimitado como sumo principio del cosmos, a partir del cual surge la totalidad de las cosas que integran el mundo y participan del mismo. Dichas entidades, a diferencia de su principio generador, cuentan con una existencia temporalmente limitada, pudiendo atribuírseles instancias precisas de nacimiento y extinción.

Las notorias diferencias existentes entre las características predicables de lo ilimitado y la naturaleza perecedera de las cosas del mundo imponen la obligación de explicar el proceso productivo de estas últimas y las causas que lo informan. Con el objeto de satisfacer esta necesidad, se expondrán y analizarán los principales aspectos de la cosmogonía de Anaximandro y las discusiones surgidas en razón de ellos.

En primer término, debe admitirse la ocurrencia de un acto de segregación, a partir del cual la materia formativa del mundo se separa desde lo ilimitado. Sin embargo, existe una serie de discrepancias entre los autores en torno a la determinación de las causas y circunstancias en que dicho proceso se produce y a la posibilidad de que este pueda repetirse de forma indefinida.

Algunos fragmentos de la obra de Aristóteles (Física $\Theta 1$, 250b11 y De Caelo B13) -y los respectivos comentarios atribuidos a Teofrasto- $-{ }^{47}$ señalan como explicación primordial de este fenómeno el hecho de que lo ilimitado correspondería a una realidad que se encuentra en un m ovi m i e n to e t e r n o, semejante a un vórtice, a partir del cual resultaría posible la disgregación antedicha ${ }^{48}$. Si bien esta tesis ofrece una explicación plausible para el acto de separación a partir del $\alpha ̋ \pi \varepsilon\llcorner @ O V$, la opinión más extendida entre los autores contemporáneos sostiene que correspondería a una formulación anacrónica respecto de la doctrina de Anaximandro, puesto que lo ilimitado, en razón de su naturaleza divina, está "dotado de capacidad de moverse y de mover a su voluntad, de modo que posee la facultad

${ }^{45}$ En un sentido similar, véase AsmIs, Elizabeth, What is Anaximander's Apeiron?, en Journal of the History of Philosophy, 19/3 (1981), pp. 287-293; BERnABÉ, Alberto, cit. (n. 4), pp. 51-52; JAEGER, Werner, La teología, cit. (n. 4), pp. 35-39; KAHN, Charles, cit. (n. 4), pp. 235-236 y NieTzSCHE, Friedrich, cit. (n. 3), pp. 51-52.

${ }^{46} \mathrm{La}$ imposibilidad de supeditar lo ilimitado a la necesidad de surgir desde un principio originario y la atribución consecuencial de este carácter a dicha sustancia se sustenta, según algunos de los autores citados, en el fragmento 203b de la Física de Aristóteles, en el cual se sostiene que "porque todas las cosas son un principio o desde un principio. Pero de lo ilimitado no hay principio". Esta traducción ha sido realizada por quien suscribe a partir del texto citado en inglés por Asmis, Elizabeth, cit. (n. 45), p. 287.

${ }^{47} \mathrm{La}$ identificación de los fragmentos aristotélicos y la alusión a los comentarios de su discípulo constan en KirK, Geoffrey; Raven, John; SchOfield, Malcolm, cit. (n. 8), pp. 189190. Para una referencia a textos doxográficos adicionales que aludan al movimiento eterno, véase KAHN, Charles, cit. (n. 4), pp. 39-40.

${ }^{48}$ A modo ejemplar, véase Engmann, Joyce, cit. (n. 37), pp. 12-13 y GuTHRIE, William, cit. (n. 4), pp. 36-37. KAHN, Charles, cit. (n. 4), p. 41 y SEAFORD, Richard, cit. (n. 4), p. 193, ofrecen una breve alusión a esta tesis, enfatizando el primero de ellos en su reconocimiento por parte de Teofrasto y Simplicio. 
de propiciar los cambios de las cosas" ${ }^{49}$, es decir, no requeriría encontrarse en un movimiento único e interminable para dar lugar a las instancias generadoras ${ }^{50}$.

En segundo término, con independencia de las causas motivadoras que se atribuyan al acto de segregación, es necesario determinar la identidad y naturaleza de aquello que surge desde lo ilimitado. En este sentido, los autores coinciden en señalar a ciertas sustancias primigenias, denominadas "opuestos" o "contrarios", como las entidades disgregadas del ăteııov.

Aun cuando lo anterior corresponde a un aspecto común entre los diversos comentaristas, algunos de ellos sostienen que los opuestos se habrían originado a partir de una especie de semilla cós mica, la cual provendría desde el interior del $\alpha$ $\tau \varepsilon$ Loov y se habría separado de este mediante un proceso de expulsión ${ }^{51}$. Con todo, esta afirmación representa una posición minoritaria en la doctrina especializada.

En términos generales, los opuestos corresponden a ciertas entidades o cualidades -dichas nociones aparecen como indiferenciadas en la tradición presocrática- ${ }^{52}$ surgidas a partir de la separación directa o indirecta desde el interior de lo ilimi$\operatorname{tado}^{53}$, adquiriendo una existencia propia e individualizada.

A partir de lo señalado por Teofrasto (Comentario sobre la Física de Aristóteles 24, 13) y Pseudo-Plutarco (Miscelánea 2 [A 10]), es posible sostener que los opuestos se organizan en dinámicas de dualidad, en las cuales cada uno de sus componentes se define en función de las diferencias radicales que lo distinguen de su contrario ${ }^{54}$. Esta afirmación se desprende de lo sostenido por el primero de los doxógrafos mencionados, el cual, en las líneas finales del pasaje de su autoría

${ }^{49}$ Bernabé, Alberto, cit. (n. 4), p. 52.

${ }^{50}$ En el mismo sentido, Kirk, Geoffrey; Raven, John; Schofield, Malcolm, cit. (n. 8), pp. 190-191. Con todo, dichos autores atribuyen esta imprecisión exclusivamente a Teofrasto, quien la habría extendido a los comentarios aristotélicos al interpretarlos en función de sus postulados filosóficos particulares.

${ }^{51}$ Freudenthal, Gad, The Theory of the Opposites and an Ordered Universe: Physics and Metaphysics in Anaximander, en Phronesis, 31/3 (1986), p. 224 y GuTHrie, William, cit. (n. 4), pp. 36-37. Para una breve referencia a estas tesis, véase KAHN, Charles, cit. (n. 4), p. 41 y Kirk, Geoffrey; Raven, John; Schofield, Malcolm, cit. (n. 8), pp. 196-197. Los últimos autores citados sostienen que la mayoría de estas formulaciones habrían surgido a partir de una metáfora prevista por Pseudo-Plutarco (Miscelánea 2 [A 10]), la cual se vincula con ciertos procesos de generación biológica.

${ }^{52}$ En este sentido, BERNABÉ, Alberto, cit. (n. 4), p. 52, sostiene que Anaximandro habría sido incapaz de efectuar una distinción precisa entre las nociones de entidad y cualidad, toda vez que dicha sistematización es propia de los postulados aristotélicos. En razón de lo anterior, el filósofo milesio habría caracterizado a los contrarios como entidades. Esta precisión adquiere especial relevancia si se tiene presente que las denominaciones usualmente asignadas por los doxógrafos a los contrarios -las cuales serán señaladas en los párrafos siguientes de este acápite- se adecúan más precisamente con la noción de cualidades predicables de ciertas sustancias.

${ }^{53}$ Kirk, Geoffrey; Raven, John; Schofield, Malcolm, cit. (n. 8), pp. 192-195, exponen brevemente los postulados de Aristóteles (Física A4, 187 a 20) y de Teofrasto (Comentario sobre la Física de Aristóteles 24, 21), quienes sostuvieron, respectivamente, que los opuestos se habrían separado desde el interior o desde el exterior de lo ilimitado. Asimismo, los autores citados dan cuenta de los inconvenientes asociados a cada una de estas posturas.

${ }^{54}$ A este respecto, Kaufmann, Arthur, cit. (n. 2), p. 52, plantea la noción de 
previamente individualizado, afirma que "los contrarios son: caliente-frío, secohúmedo y los demás" $"$. Sin perjuicio del carácter meramente ejemplar de la enumeración referida por el filósofo neoplatónico -evidenciada por la inclusión de la expresión "y los demás”-, las parejas de opuestos enunciadas de forma expresa corresponden a aquellas usualmente identificadas por los pensadores presocráti$\cos ^{56}$ y las aludidas por Aristóteles como sustancias constitutivas de los elementos ( $\sigma \tau о\llcorner\chi \varepsilon \tilde{\imath} \alpha v)$, en el sentido cosmológico acuñado por Platón ${ }^{57}$.

Los opuestos, una vez que se han separado de lo ilimitado, se relacionan entre sí a partir de una dinámica consistente en una sucesión de invasiones o transgresiones recíprocas del espacio o porción de la materia existente que le corresponde a su correlativo ${ }^{58}$. Si bien se admite que estas interacciones están determinadas por la intención o tendencia natural a imponerse absolutamente respecto de su contrario, dicho supuesto resulta generalmente impedido por ciertas fuerzas o principios - provenientes desde el ö́rદı@ov, al igual que las sustancias que componen el universo- encargados de restituir la posición original del opuesto vulnerado y, consecuencialmente, posibilitar que este lleve a cabo un "acto de agresión" en sentido contrario ${ }^{59}$.

Aun cuando las tendencias transgresoras inherentes a las relaciones entre los opuestos pudiesen reputarse como perniciosas, toda vez que implicarían el reconocimiento de una lógica de contradicción agonal y de la ruptura del orden proporcional o equitativo en que se encontraban dispuestas las sustancias al momento de disgregarse de lo ilimitado ${ }^{60}$, esta dinámica resulta indispensable para la vigencia efectiva de los presupuestos del devenir.

"p e n s a mi e n t o b i p o la r", el cual identifica como un rasgo distintivo de la filosofía del período presocrático.

${ }^{55}$ Pseudo-Plutarco, en el fragmento citado en lo principal, alude a uno de los binomios señalados por Simplicio, al afirmar que "asimismo que lo que es productivo de calor y frío en el origen de este mundo [...]”. La transcripción ha sido extraída desde BernabÉ, Alberto, cit. (n. 4), pp. 56-57.

${ }^{56}$ Así, Kirk, Geoffrey; Raven, John; Schofield, Malcolm, cit. (n. 8), pp. 180-181, sostienen que dichos opuestos habrían sido reconocidos, posteriormente, por diversos filósofos presocráticos, en especial Heráclito y Empédocles. Junto con lo anterior, los autores citados enuncian otras parejas de opuestos que podrían haber sido propuestas por Anaximandro.

${ }^{57}$ Reconoce el vínculo existente entre ambas categorías filosóficas, entre otros, KAHN, Charles, cit. (n. 4), pp. 126-127. Para una breve referencia del sentido cosmológico que Platón atribuye

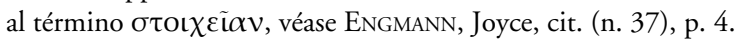

${ }^{58} \mathrm{El}$ análisis e interpretación de las consecuencias derivadas de esta clase de dinámicas relacionales y de los principios que determinan su desarrollo serán abordados detalladamente en la sección siguiente del presente acápite.

${ }^{59}$ Para una descripción general de esta dinámica, véase, entre otros, BERnABÉ, Alberto, cit. (n. 4), pp. 52-53; Engmann, Joyce, cit. (n. 37), pp. 12-13; Freudenthal, Gad, cit. (n. 51), pp. 208-209 y KiRK, Geoffrey; Raven, John; SCHOfield, Malcolm, cit. (n. 8), pp. 179-181. Estos últimos autores ofrecen algunos ejemplos de relaciones naturales de oposición -v. gr. calor y sequedad del verano respecto del frío y lluvia del invierno- que habrían inspirado la teoría de Anaximandro y, a su vez, permitirían apreciar la efectividad de la afirmación relativa a la imposibilidad general de la transgresión definitiva de un opuesto en desmedro de su contrario.

${ }^{60}$ En relación con este tópico, Engmann, Joyce, cit. (n. 37), pp. 19-21 y Freudenthal, Gad, cit. (n. 51), pp. 199 y 207, aluden al artículo de VLASTOS, Gregory, Equality and Justice 
Por una parte, los aspectos esenciales de la teoría cosmogónica de Anaximandro se estructuran a partir de las relaciones de confrontación entre los opuestos y de los principios asociados a éstas, especialmente en lo relativo al proceso de desecación de la humedad primigenia de la tierra, como consecuencia del influjo del calor irradiado desde la corteza incandescente que la rodea, y a la ocurrencia de variados fenómenos meteorológicos ${ }^{61}$.

Por otra parte, las conductas de agresión y reparación en que incurren los opuestos corresponden a las condiciones de posibilidad de los cambios sucesivos asociados al devenir, los cuales concluyen con el perecimiento o destrucción de los contrarios y de todo cuanto ha surgido a partir de ellos ${ }^{62}$. En la teoría de Anaximandro, el momento cúlmine de la existencia individual de las cosas, al igual que el de origen del cosmos, se reconduce al $\alpha$ $\tau \varepsilon\llcorner\varrho O V$, toda vez que, según el texto atribuido a la sentencia del filósofo de Mileto, "las cosas perecen en lo mismo que les dio el ser, según la necesidad"63.

El carácter cíclico de las instancias de nacimiento y destrucción del mundo y de las cosas existentes en él corresponde a una manifestación de la naturaleza eterna y divina de la sustancia originaria ${ }^{64}$, toda vez que la ocurrencia de dichos

in Early Greek Cosmologies, en Classical Philology, 42 (1947), 3, pp. 156-178, en el cual se adscribe a la distribución cosmogónica equitativa entre los opuestos. Dicha tesis es desestimada completamente por el primer autor citado, mientras que es parcialmente validada por el segundo de ellos.

${ }^{61}$ La mayoría de los tratadistas en esta materia prevé una exposición de los aspectos principales de la cosmogonía y cosmología de Anaximandro. Entre otros, véase BERNABÉ, Alberto, cit. (n. 4), p. 54; Guthrie, William, cit. (n. 4), pp. 36-38; KaHN, Charles, cit. (n. 4), pp. 75-109; KIRK, Geoffrey; Raven, John; Schofield, Malcolm, cit. (n. 8), pp. 195-208 y NieTzSche, Friedrich, cit. (n. 3), pp. 52-53. En lo sucesivo de este artículo sólo se incluirán referencias aisladas a este aspecto de la teoría del filósofo milesio, puesto que no constituye uno de los objetos de análisis de la presente investigación.

${ }^{62}$ A este respecto, resulta interesante la interpretación planteada por FrEUDENTHAL, Gad, cit. (n. 51), p. 223, según la cual las cosas, al momento de perecer, se deshidratan y adquieren forma de polvo, al igual que la sustancia desde la cual se originaron. En este sentido, la sección de la sentencia citada en las líneas siguientes de este párrafo debiese reconducirse a una explicación de carácter eminentemente físico, en desmedro de interpretaciones de índole metafórico. Con todo, dicha propuesta no cuenta con sustento sólido en los planteamientos de Anaximandro y de sus principales comentaristas.

${ }^{63}$ Entre las interpretaciones propuestas para el uso de la expresión "necesidad” en la sentencia de Anaximandro, adquiere especial importancia lo planteado por OPPERMANN, Jan, cit. (n. 31), p. 49, quien entiende que las dinámicas cósmicas deben ocurrir de forma ineludible y constante -necesariamente-, sin que la expresión en comentario deba entenderse utilizada en relación con la existencia de alguna entidad o principio que desempeñe funciones esenciales en la ocurrencia de dichos procesos. En un sentido similar, véase HeIDEgGer, Martin, The Beginning, cit. (n. 40), p. 8, quien, además de lo anterior, sostiene que la necesidad permite asegurar que el devenir no quede supeditado a "la elección o placer de los entes", en tanto posibilidad de sea aceptado o rechazado por estos.

${ }^{64}$ En este sentido, Heidegger, Martin, The Beginning, cit. (n. 40), pp. 9-10 y Oppermann, Jan, cit. (n. 31), pp. 47-50. El primero de ellos sostiene que los opuestos se reconocen cierta reciprocidad, en virtud de un sistema constante de "relaciones de llegada y de salida", mientras que el segundo afirma que existe una especie de ritmo o constante cósmica basada en la alternancia periódica de "llegar a ser y dejar de ser". 
fenómenos y sus efectos se reconducen de forma ineludible a lo ilimitado. Asimismo, la viabilidad de reiteración de la ocurrencia de los eventos de inicio y término de la existencia de los entes derivados del principio cosmológico opera como condición de posibilidad de las cuestiones expuestas en los párrafos inmediatamente anteriores.

A partir de lo señalado, es posible exponer y comentar brevemente algunas consideraciones planteadas en esta materia, las cuales dan cuenta del carácter diverso y multidisciplinario de las interpretaciones formulables respecto de la teoría cosmogónica de Anaximandro y de las implicancias derivadas de éstas.

Con respecto a las proyecciones de carácter cosmológico, específicamente en lo relativo al vínculo que se verifica entre el $\alpha$ $\pi \varepsilon \iota$ Łov, en tanto entidad de índole divina, y los procesos de origen y perecimiento de los opuestos y de las demás cosas existentes, se han planteado múltiples teorías interpretativas, especialmente entre los estudiosos contemporáneos del filósofo milesio ${ }^{65}$.

En primer lugar, E. Asmis propone una "interpretación monista”, en virtud de la cual el carácter imperecedero de lo ilimitado obliga a unificarlo con la sucesión ininterrumpida de cosas generadas, en tanto surgen y se destruyen cíclicamente $^{66}$. A pesar de las suspicacias que pudiese suscitar la originalidad de esta propuesta, la autora conjuga adecuadamente las características inherentes a las figuras antes señaladas y sustenta sus afirmaciones en diversos fragmentos de filósofos y doxógrafos clásicos.

En segundo lugar, J. Engmann, al igual que la autora precedente, afirma la existencia de un vínculo permanente entre el principio originario y las cosas surgidas directa o indirectamente desde él, sin embargo, dicha relación no implica una asimilación de ambas figuras, sino que corresponde a un "intercambio material" constante entre lo ilimitado y la dinámica cíclica de nacimiento y destrucción. En consecuencia, dichos momentos no presuponen la ocurrencia de eventos cosmogónicos o cataclísmicos, respectivamente, sino que pueden operar a niveles intermedios o inferiores, sin que por ello se afecte el devenir del mundo en su totalidad ${ }^{67}$.

En tercer lugar, G. Freudenthal sostiene que el orden natural del mundo, en relación con los presupuestos básicos de la teoría de los opuestos, no puede atribuirse a un equilibrio auto-impuesto o regulado por las propias sustancias inmanentes, sino que debe provenir necesariamente desde factores externos correspondientes, en último término, a lo ilimitado ${ }^{68}$.

Lo propuesto por este autor resulta plenamente concordante con la naturaleza inmanente de los opuestos y de las cosas surgidas a partir de estos, toda vez que su sometimiento a la lógica del devenir requiere, como antecedente necesario, la existencia de instancias de nacimiento y destrucción que no dependan ni se

\footnotetext{
${ }^{65}$ Sin perjuicio de la relevancia y significación académicas de las opiniones que serán referidas en los párrafos siguientes, éstas no serán sometidas a un análisis exhaustivo, toda vez que ello excedería considerablemente el objetivo principal del presente artículo.

${ }^{66}$ Asmis, Elizabeth, cit. (n. 45), pp. 279-297.

${ }^{67}$ EngmanN, Joyce, cit. (n. 37), pp. 14-19.

${ }^{68}$ Freudenthal, Gad, cit. (n. 51), pp. 197-228.
} 
estructuren a partir de la regulación que dichas entidades puedan atribuirse a sí mismas. En caso contrario, el mundo y las cosas existentes podrían adquirir un carácter trascendente e invariable, participando de las cualidades que deben predicarse exclusivamente de lo ilimitado.

Junto con los postulados anteriormente expuestos, es posible identificar algunas propuestas hermenéuticas que, sin perjuicio de compartir el objeto de estudio con las tesis cosmológicas, proyectan sus alcances más allá del análisis históricofilosófico, específicamente en el ámbito ético y jurídico.

Por una parte, M. Heidegger, en su artículo La sentencia de Anaximandro ${ }^{69}$, sostiene una particular interpretación sobre las interacciones entre los opuestos y la manera en que debe entenderse el perecimiento de las cosas. Así, dicho filósofo describe la dinámica de nacimiento y destrucción a partir de las ideas de p re sencia y ausencia en lo presente, respectivamente.

En este sentido, en el lapso que media entre el origen y el perecimiento, aquello que existe "mora un tiempo" en la presencia de lo presente y, ante la inminencia del tránsito hacia lo ausente, persiste en su posición, procurando mantenerse en su morada y, en consecuencia, transgrede el ámbito de presencia que le corresponde a sus semejantes. Con todo, el momento de perecer puede y debe ser admitido como una etapa necesaria y deseable en el ciclo del devenir, por lo que las cosas deben evitar la persistencia en lo presente, propendiendo al acuerdo y, en caso de que la transgresión ocurra indefectiblemente, obligarse a procurar una reparación al des-acuerdo, basada en la atención mutua ${ }^{70}$.

La fundamentación de dicha propuesta exegética se desprende de la traducción

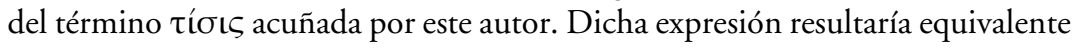
a "estima" o "consideración", a diferencia de las posturas tradicionales, que entienden la locución griega como sinónimo de "expiación" o "pago"71. El efecto práctico derivado de este ejercicio de traslación se materializa en la sustitución del sentido punitivo comúnmente atribuido al concepto en análisis por uno de carácter ético o vinculado con cierto sentido de moralidad propio del carácter comunitario de la vida en sociedad ${ }^{72}$.

Aun cuando la interpretación heideggeriana pueda resultar interesante o innovadora, es preciso advertir que se sustenta en la aplicación de categorías propias y de razonamientos que no cuentan con un respaldo suficiente en el texto del fragmento atribuido al filósofo milesio, salvo por el sentido imputable a algunas expresiones griegas y sus traducciones al idioma alemán.

${ }^{69} \mathrm{La}$ interpretación desarrollada en dicho texto se encuentra reproducida prácticamente en idénticos términos en HeIdegger, Martin, The Beginning, cit. (n. 40), pp. 9-13. Asimismo, Oppermann, Jan, cit. (n. 31), pp. 56-63, adhiere a la tesis que será expuesta en los párrafos sucesivos.

${ }^{70}$ Para el planteamiento de la interpretación del filósofo alemán, véase HEIDEGGER, Martin, La sentencia, cit. (n. 7), pp. 253-276.

${ }^{71}$ Heidegger, Martin, La sentencia, cit. (n. 7), pp. 266-268.

${ }^{72}$ En este sentido, Oppermann, Jan, cit. (n. 31), p. 63, sintetiza la propuesta de M. Heidegger mediante la formulación de la actitud que debiesen adoptar las cosas que componen el mundo, la cual podría expresarse a través de la frase "esto realmente le pertenece a él y yo debo permitir que le pertenezca”. 
Esta constatación resulta contradictoria con la exhortación contenida en el mismo texto, relativa a "pensar griegamente el pensar de los griegos"73. Sin embargo, la adopción de esta propuesta se explica a partir de lo señalado por M. Ávila Vásquez, para quien la lectura en comentario -publicada originalmente en 1946-, al igual que otras interpretaciones de M. Heidegger formuladas en los años inmediatamente anteriores a ésta, se ven influenciadas por los acontecimientos ocurridos durante la Segunda Guerra Mundial y las horribles consecuencias derivadas de $\operatorname{estos}^{74}$.

Por otra parte, desde una perspectiva eminentemente iusfilosófica, A. Kaufmann ha sostenido que la sentencia de Anaximandro corresponde a la "concepción jurídica más antigua de Occidente" 75 . Sin perjuicio de que las consecuencias de esta afirmación pueden proyectarse sobre diversos ámbitos del derecho, en los párrafos sucesivos se expondrán exclusivamente aquellos argumentos que permitan sostener que dicho autor habría identificado un vínculo entre los postulados del filósofo de Mileto y el reconocimiento de una ley natural.

No obstante la brevedad del pasaje dedicado por el jurista alemán a la figura de Anaximandro, es posible distinguir en él dos momentos textuales, los cuales consisten en la identificación de la existencia de un orden en el cos mos y de un derecho a sero exigencia de autoafirmación.

El primero de dichos tópicos presupone la aceptación de las consideraciones cosmogónicas y cosmológicas previamente enunciadas en este acápite, ya que el autor en comentario señala que "todo lo que es, es también, como ente, dentro de un orden"76. La referencia final incluida en esta cita debe entenderse hecha al rol de lo ilimitado en la organización cósmica, al devenir como principio rector universal y a las dinámicas derivadas de este.

Con todo, dicho fragmento sólo puede ser interpretado de forma correcta si se aprecia conjuntamente con otra sección del comentario de A. Kaufmann, en la que se advierte que "Anaximandro [...] distingue, en este sentido, ser y orden (hoy decimos ser y deber ser), pero vistos aún como unidad [...]”77. La aclaración incluida entre paréntesis permite sostener que la noción de orden cuenta con implicancias normativas, en virtud de las cuales podría reputarse como equivalente a consideraciones propias de instituciones de carácter deontológico.

La conjunción de ambas interpretaciones permite sostener que la normativi-

${ }^{73}$ La transgresión de esta premisa autoimpuesta no se verifica exclusivamente en la interpretación heideggeriana de las relaciones recíprocas entre los opuestos, sino que también puede advertirse en la relevancia trascendental que dicho autor reconoce al concepto de "lo ente" ( $\tau \dot{\alpha}$ óv $\tau \alpha)$ como criterio interpretativo de la sentencia de Anaximandro. Vid. HeIDEgGer, Martin, La sentencia, cit. (n. 7), pp. 246-252. Con el objeto de sustentar esta afirmación, es necesario tener presente el carácter fundamental y distintivo que las consideraciones en torno al Ser y los entes representan para la obra filosófica de M. Heidegger.

${ }^{74}$ Ávila Vásquez, Manuel, cit. (n. 14), pp. 79-82. En las páginas referidas, además de la tesis señalada en lo principal, se exponen las consecuencias de las explicaciones pesimistas y superadoras planteadas por M. Heidegger respecto de la sentencia de Anaximandro.

${ }^{75}$ Kaufmann, Arthur, cit. (n. 2), p. 52.

${ }^{76}$ Ibíd.

${ }^{77}$ Ibíd. 
dad previamente señalada, la cual constituiría o permitiría coordinar los cánones inherentes a la noción de "deber ser", se condice con el orden natural del cosmos y con las máximas que regulan su existencia una vez que se ha producido la separación desde lo ilimitado.

En un sentido diverso, esta relación puede describirse a partir del carácter fundante de la estructura cosmológica en relación con las normas deónticas, toda vez que estas últimas constituirían manifestaciones concretas de aquélla, por lo que en último término, el parámetro de adecuación definitivo correspondería al

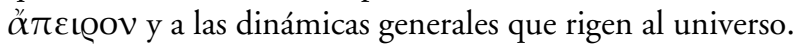

El segundo tópico referido por A. Kaufmann dice relación con el estatuto que debe atribuirse a los seres que componen el mundo y la posibilidad de identificar una especie de actitud que éstos debiesen asumir en sus interacciones cotidianas. Así, el filósofo germano señala que "con el existir se da también el derecho a ser y a ser de una determinada manera, una exigencia de autoafirmación del propio ser, y que, por lo tanto, es preciso dejar a los otros ser como son"78.

Dicha "declaración filosófico-existencial" posee ciertas similitudes con la interpretación propuesta por M. Heidegger, puesto que enfatiza la posición que ocupan las diversas entidades -los opuestos y las cosas surgidas a partir de sus relaciones agonales- en el espacio, tanto en un sentido naturalista como desde una perspectiva ética, y en la necesidad impuesta a cada una de ellas en torno a considerar la existencia individual y los intereses de sus semejantes.

No obstante lo anterior, el fragmento en comentario representa una superación de la exégesis propuesta por este último filósofo, específicamente en lo relativo a las expresiones utilizadas y a las consecuencias prácticas derivadas de éstas. A pesar de que ambas tesis poseen contenido ético y moral, la propuesta de A. Kaufmann no implica una reformulación de la sentencia de Anaximandro ni una adecuación a categorías filosóficas impropias de la época del pensador milesio, sino que se limita a vincularla con ciertas consideraciones posteriores a partir de un ejercicio hermenéutico de carácter externo, sin modificar o alterar su contenido ${ }^{79}$.

Junto con lo anterior, el fragmento en análisis prevé consideraciones de índole jurídica relativas a la titularidad de ciertos derechos y deberes, la cual es reconocida a las diversas especies de seres surgidos desde lo ilimitado. Los vínculos jurídicos articulados a partir de lo anterior no se sustentan en un ordenamiento legal positivo, sino que están referidos a aspectos esenciales de la existencia de sus titulares, específicamente, el "derecho a ser" de cada entidad y los deberes correlativos exigibles a sus semejantes.

Estas consideraciones revisten interés no sólo por la incorporación explícita de términos propios de la disciplina del derecho, sino porque, adicionalmente, permiten advertir las implicancias derivadas del reconocimiento generalizado - no limitado exclusivamente a los individuos de la especie humana- de una aptitud

\footnotetext{
${ }^{78}$ Ibíd.

${ }^{79} \mathrm{Sin}$ perjuicio de los aspectos positivos reconocidos al texto de A. Kaufmann, es preciso señalar que la labor interpretativa de M. Heidegger constituye un esfuerzo de mayor complejidad técnica, en tanto incorpora análisis filológico, consideraciones históricas y desarrolla parte importante de los tópicos de la sentencia de Anaximandro.
} 
intelectual o agencia que fundamenta la atribución de los derechos previamente señalados y de una especie de conciencia moral en que se sustentan la "autoafirmación del ser" y la exigibilidad de ciertos deberes relativos al respeto por la existencia de los otros ${ }^{80}$.

De esta manera, la interpretación de A. Kaufmann hace posible sostener que la posición de los entes en el cosmos, a partir de la cual se establecen derechos y deberes de carácter jurídico, obedece a un orden natural preestablecido y derivado desde lo ilimitado. A partir de lo anterior, los supuestos de transgresión entre opuestos pueden entenderse como vulneraciones de los estándares deónticos impuestos por dicho orden, las cuales deben ser contrarrestadas mediante reparaciones recíprocas determinadas por parámetros universales. Estas dinámicas presentan semejanzas importantes con las principales características atribuidas al derecho natural y sus leyes, dentro de las que destacan su carácter universal e inmutable, la identificación de su fuente originaria en una realidad superior a la voluntad humana y el reconocimiento de un deber jurídico relativo al respeto por la vida propia y la del prójimo ${ }^{81}$.

Sin perjuicio de la eventual discusión que podría originarse a partir de la relación propuesta en el párrafo precedente ${ }^{82}$, es necesario reconocer que dicha interpretación del texto de A. Kaufmann posibilita afirmar la existencia indiscutible de un vínculo entre la sentencia de Anaximandro y cuestiones propias de la filosofía y teoría general del derecho.

A modo de síntesis de la presente sección, es posible sostener que las tesis cosmogónica y del devenir, formuladas a partir de las características atribuidas a lo ilimitado, constituyen uno de los aspectos principales de la filosofía de Anaximandro y una manifestación de la mayor sutileza y complejidad comparativas de su pensamiento en relación con el de los demás filósofos presocráticos del siglo VI a.C. ${ }^{83}$ Esta última característica permite la formulación de diversas propuestas

${ }^{80}$ La dinámica de derechos y deberes antes descrita y el fundamento en que se sustenta permiten sostener que las agresiones cometidas en el marco de las relaciones de confrontación entre los opuestos constituyen actos deliberados y que, en consecuencia, corresponden a infracciones del deber de respeto por los semejantes, las cuales debiesen reputarse merecedoras de la sanción prevista al efecto. Estas consideraciones se relacionan directamente con las cuestiones que serán abordadas en la siguiente sección de este artículo.

${ }^{81}$ Para un examen de los principios y características del derecho natural, véase PACHECO Gómez, Máximo, Teoría del derecho (4a ed., Santiago, Editorial Jurídica de Chile, 1990), pp. 463-466. A modo de complemento, considérese la exposición prevista a este respecto en Hervada Xiberta, Javier, Introducción crítica al derecho natural (11 a ed., Pamplona, Ediciones Universidad de Navarra, 2011), pp. 137-141.

${ }^{82}$ A modo de ejemplo, JaEger, Werner, Paideia, cit. (n. 4), p. 159, a pesar de consentir en la "prodigiosa idea de una legalidad universal de la naturaleza", desestima que ésta se trate de una ley natural, sino que correspondería a una "norma universal" justificante de la naturaleza ordenada del cosmos.

${ }^{83}$ Adscriben a estas últimas consideraciones, entre otros, BERNABÉ, Alberto, cit. (n. 4), p. 55; Guthrie, William, cit. (n. 4), pp. 35-39 y Jaeger, Werner, Paideia, cit. (n. 4), pp. 156-160. Con todo, Nietzsche, Friedrich, cit. (n. 3), pp. 52-53, considera que, salvo por los planteamientos relativos al $\alpha$ $\pi \varepsilon\llcorner\varrho o v$, las demás ideas físicas de Anaximandro corresponden a 
interpretativas, las cuales se estructuran a partir de consideraciones y perspectivas multidisciplinarias.

\section{La noción de justicia en Anaximandro. Injusticia, retribución y disposición} del tiempo

En la sección precedente de este acápite se han expuesto los aspectos esenciales del principio cósmico identificado por Anaximandro, de los procesos cosmológicos que ocurren a partir de este y de la dinámica de alternancia entre nacimiento y destrucción de todo aquello surgido, mediata o inmediatamente, desde lo ilimitado.

Con respecto a esta última cuestión, al momento de analizar las interacciones que se verifican entre los opuestos y entre las cosas surgidas a partir de estos, se advirtió una tendencia a la comisión de ciertas transgresiones recíprocas en desmedro del elemento contrario correspondiente, las cuales reconocen como "objetivo ideal" la dominación total e irreversible de la entidad agredida. Tanto lo descrito en este párrafo como el perecimiento ineludible en lo ilimitado, predicable de todas las cosas constitutivas del mundo, se encuentran vinculados a ciertos principios y consideraciones generales identificables en algunas de las expresiones utilizadas en la sentencia de Anaximandro, específicamente aquellas que aluden a la "injusticia", "justa retribución” y "disposición del tiempo".

No obstante lo sostenido en los pasajes finales de la sección anterior, las implicancias de naturaleza jurídica más relevantes que pueden extraerse a partir de la sentencia de Anaximandro dicen relación con la noción de justicia y con los demás conceptos relacionados que fueron señalados en el párrafo precedente.

La mayoría de los intérpretes del filósofo milesio concuerdan en reconocer una especie de c a rá c te r i n j u s to asociado a la existencia individual de las cosas fuera de lo ilimitado, sin perjuicio de lo cual, no existe pleno acuerdo en torno a precisar en qué consistiría dicha injusticia.

Por una parte, las interpretaciones tradicionales asociaban dicha injusticia ( $\alpha \delta \iota \kappa i ́ \alpha \varsigma)$ a la existencia individual en sí misma, toda vez que ésta correspondería a una separación desde la unidad de lo eterno y divino, una ruptura con el principio originario en el cual residen el orden y la justicia. En este sentido, las cosas inmanentes deben expiar una especie de c u l p a o rig in a r i a, asociada a su nacimiento a partir de la disgregación desde lo ilimitado ${ }^{84}$.

Por otra parte, como alternativa a dicho análisis, se ha formulado una propuesta de exégesis en virtud de la cual se identifica la injusticia con "la prevalencia de una sustancia a expensas de su contrario" ${ }^{85}$, es decir, con las transgresiones recíprocas entre los opuestos, asociadas con el curso del devenir en la existencia.

En un sentido técnico, W. Jaeger, principal exponente de esta tesis, desestima la pertinencia de las consideraciones ético-religiosas vinculadas con la posición

una mera continuación del pensamiento de Tales de Mileto. Esta última interpretación adolece de fundamentos sólidos y, por lo tanto, aparece como infundada e insostenible.

${ }^{84}$ Véase, entre otros, Giannini, Humberto, cit. (n. 17), p. 15; KaHN, Charles, cit. (n. 4), pp. 177-178 y NieTZSCHE, Friedrich, cit. (n. 3), pp. 48-50.

${ }^{85}$ Kirk, Geoffrey; Raven, John; Schofield, Malcolm, cit. (n. 8), p. 180. 
contraria $^{86}$ y denomina a la injusticia de los opuestos como ple o n exia, es decir, la tendencia natural al exceso, a "tomar más y más" ${ }^{7}$. La interpretación asociada a esta postura es preferible a la de carácter tradicional, puesto que, además de otorgar primacía a consideraciones técnicas, permite identificar con precisión una conducta que puede catalogarse como factor de a tribución de las consecuencias que se siguen del acto injusto ${ }^{88}$.

A pesar de las diferencias existentes entre ambas posturas, es posible formular una alternativa que permita concordar sus aspectos principales, la cual consiste en identificar a la pleonexia con los actos injustos cometidos por las cosas existentes y la tendencia natural de éstas a ejecutar dicha clase de conductas. De este modo, las entidades presentes en el mundo no podrían ser acusadas de injusticia atendiendo exclusivamente al hecho de disgregarse de lo ilimitado, sin embargo, desde el momento en que dicha separación tiene lugar, aquellas existencias actúan impulsadas por una predisposición al exceso y, en consecuencia, a la comisión de actos injustos ${ }^{89}$.

La idea de injusticia impone la necesidad lógica y consecuencial de admitir la posible verificación efectiva de la noción de justicia ( $\delta i ́ \kappa \eta)$, en tanto principio contrapuesto a partir del cual se determinan e imponen las consecuencias adversas asociadas a los actos injustos ${ }^{90}$.

La mayoría de los intérpretes considera a la justicia en Anaximandro como una noción de índole cósmica, surgida desde lo ilimitado y de carácter absoluto e inquebrantable, en virtud de la cual se organiza y ordena la totalidad del universo ${ }^{91}$. Esta descripción del orden del cosmos, al igual que la mayoría de los aspectos previstos en la sentencia de Anaximandro, se estructura a partir de una especie de metáfora respecto del orden jurídico de los seres humanos, cuya lógica interna de funcionamiento se proyecta en asuntos de naturaleza universal ${ }^{92}$.

${ }^{86}$ Aun cuando los autores que sustentan dicha posición no lo señalen expresamente, es posible advertir ciertas similitudes entre su caracterización de la injusticia en Anaximandro y la doctrina cristiana del pecado original.

${ }^{87}$ JAEGER, Werner, La teología, cit. (n. 4), pp. 39-40; Alabanza de la ley, cit. (n. 1), p. 27; Paideia, cit. (n. 4), pp. 158-159.

${ }^{88}$ En relación con el último razonamiento expuesto, véase BERNABÉ, Alberto, cit. (n. 4), pp. 52-53 y ENGMANn, Joyce, cit. (n. 37), pp. 11-12.

${ }^{89}$ Sin perjuicio de las discrepancias hermenéuticas que fueron señaladas previamente, existen algunas similitudes entre las interpretaciones propuestas para los postulados de W. Jaeger sobre la pleonexia y los de A. Kaufmann relativos al sentido atribuible al orden cósmico y los principios que rigen las relaciones entre los opuestos.

${ }^{90}$ En oposición parcial, OPPERMANN, Jan, cit. (n. 31), pp. 53-54, en cuyo concepto, la justicia no operar por sí misma como el opuesto natural de la injusticia, sino que debe interpretarse

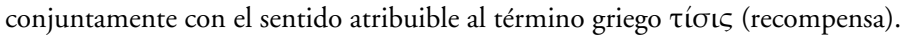

${ }^{91}$ Así, Freudenthal, Gad, cit. (n. 51), p. 209; García Belaúnde, Domingo, La justicia en los orígenes de la filosofía del derecho, en Revista de Derecho de la Pontificia Universidad Católica del Perú, 32 (1974), p. 142 y Jaeger, Werner, Alabanza de la ley, cit. (n. 1), pp. 24-25 y Paideia, cit. (n. 4), pp. 159 y 163.

${ }^{92}$ En radical oposición, Heidegger, Martin, The Beginning, cit. (n. 40), pp. 10-11, a cuyo juicio el sentido jurídico-moral de la dicotomía justicia-injusticia, de carácter terrenal, no resulta adecuado a una doctrina cosmológica como la del filósofo de Mileto. 
En virtud de la necesidad de un imperio irrestricto de la justicia, se impone el deber a las cosas existentes, en tanto actúan motivadas por sus tendencias pleonéxicas, de darse “justa retribución por su injusticia”. Como señalan G. Kirk, J. Raven y M. Schofield, el deber de retribución impuesto por la justicia cósmica es de c a rá c t e r m u t u o, lo cual se explica en función de la dinámica de transgresiones sucesivas y alternativas en que incurren los opuestos ${ }^{93}$.

Asimismo, los autores citados descartan cualquier interpretación que haga posible admitir que dicha relación conmutativa pueda verificarse entre los individuos existentes y lo ilimitado, puesto que "las cosas que cometen injusticia deben ser iguales entre sí, diferentes aunque correlativas; y lo más probable es que éstas sean las sustancias opuestas que componen el mundo ya diferenciado" ${ }^{\prime 4}$. De esta manera, la naturaleza divina, única e irrepetible de lo ilimitado -la cual impide que exista alguna entidad correlativa o equivalente al principio originario-, junto con la ausencia de injusticia en su existencia, inciden en que esta entidad se sustraiga de las retribuciones derivadas de las conductas pleonéxicas.

Sin perjuicio del reconocimiento de la necesidad inexorable de pagar justa retribución por las injusticias cometidas, las consideraciones antes expuestas no especifican la forma concreta en que debe darse cumplimiento a dicha obligación. En esta materia, la tesis propuesta por J. Engmann aparece como una alternativa consistente y suficientemente fundada. Este autor, a partir de la admisión de las tendencias pleonéxicas que rigen el actuar de las cosas en el mundo, distingue dos clases de conductas injustas, en razón del " grado de to le rabilidad" de las mismas ${ }^{95}$.

Por una parte, identifica aquellos actos de transgresión de menor entidad -los cuales podrían reconducirse, por ejemplo, a la sucesión de las estaciones del año o al paso del día a la noche y viceversa-, cuya reparación consiste en la restitución de aquello que le fue privado al opuesto vulnerado y, además, la posibilidad que se le debe conceder a este último de incurrir por su parte en un acto de agresión equivalente al que ha sufrido ${ }^{96}$. A partir de esta clase de relaciones se estructura la dinámica progresiva del devenir.

Con todo, el autor antes señalado reconoce una segunda clase de actos injustos, los cuales, a diferencia de las vulneraciones menores, constituyen hipótesis de dominación excesiva, no susceptibles de repararse mediante mecanismos de retribución particular. Estas transgresiones sólo pueden corregirse a partir de la imposición de la condena más elevada prevista en la doctrina de Anaximandro: el perecimiento en lo ilimitado ${ }^{97}$.

\footnotetext{
${ }^{93}$ KirK, Geoffrey; Raven, John; Schofield, Malcolm, cit. (n. 8), p. 179.

${ }^{94}$ Ibíd.

${ }^{95}$ Engmann, Joyce, cit. (n. 37), pp. 19-24.
}

${ }^{96}$ En un sentido similar, véase KIRK, Geoffrey; RAVEN, John; SCHOFIELD, Malcolm, cit. (n. 8), pp. 180-181. Dichos autores han descrito esta clase de retribución como "una restitución total, más una multa proporcionada”.

${ }^{97}$ Como ejemplo de esta clase de actos injustos, Engmann, Joyce, cit. (n. 37), pp. 2021 , señala las variaciones progresivas que se advierten en la interacción entre las sustancias cosmogónicas opuestas, cuyo momento cúlmine debiese manifestarse a través de un predominio 
Sin perjuicio de que esta última clase de actos injustos y el castigo correspondiente revisten la entidad suficiente para estimar que sólo podrían verificarse como consecuencia de eventos cataclísmicos, en los cuales debiese perecer el mundo en su totalidad, la tesis en análisis no se restringe a dichas hipótesis, sino que admite que la condena de destrucción se aplique respecto de transgresiones específicas, de gravedad considerable, que hubiesen sido cometidas con alcance restringido por entidades particulares existentes en el mundo ${ }^{98}$.

La dinámica retributiva descrita en los párrafos anteriores permite apreciar la coherencia interna de la doctrina del filósofos de Mileto, puesto que, a pesar del carácter negativo asociado a los actos injustos, tanto desde una perspectiva filosófica como jurídico-técnica, estos se reputan como un aspecto indispensable de la lógica imperante en el devenir de todo cuanto existe en el mundo segregado desde lo ilimitado.

A partir de las consideraciones antes expuestas, es posible atribuir ciertas características a la justicia cósmica de Anaximandro, además de su n a t u r a le z a s o b e r a n a a b s olut a, en virtud de la cual extiende su influencia sobre todos los aspectos de la realidad fáctica universal.

Las diversas modalidades de reparación establecidas respecto de los actos injustos permiten calificarla como una especie de justicia punitiva de c a rá c te r r e t r i b u t i vo, toda vez que impone consecuencias desfavorables al sujeto agresor -deber de soportar un acto de agresión correspondiente o su destrucción absoluta-, las cuales deben ser equivalentes a la magnitud del daño producido, con el objeto de restituir la vigencia del orden existente antes de la ocurrencia de dichos actos de transgresión ${ }^{99}$.

Asimismo, la caracterización ofrecida a propósito de los actos pleonéxicos, en conjunto con ciertas consideraciones históricas relativas al sistema jurídico imperante en la Grecia arcaica, permiten sostener que la justicia cósmica no podría equiparase a los paradigmas contemporáneos de equidad o igualdad, sino que debiese asimilarse a las concepciones imperantes en ciertos modelos jurídicos aristocráticos, según las cuales la injusticia de los actos vendría dada por la tendencia a obtener más de lo que corresponde según el orden establecido, aun cuando esto implicase legitimar hipótesis de desequilibrio material o inequidad ${ }^{100}$.

No obstante lo anterior, la retribución cósmica no puede interpretarse como una manifestación de la lógica talional, ya que no es admisible que la corrección de una injusticia se practique mediante un acto de idéntica naturaleza, sino que

absoluto de lo cálido por sobre los demás elementos. Asimismo, FreUdENTHAL, Gad, cit. (n. 51), p. 220, prevé consideraciones en el mismo sentido respecto de la hipótesis señalada.

${ }^{98}$ Dicha interpretación se sustenta a partir de la tesis de J. Engmann referida en la sección precedente de este acápite, según la cual la relación existente entre lo ilimitado y aquello surgido a partir de él consiste en una sucesión ininterrumpida de instancias de nacimiento y destrucción.

${ }^{99}$ En un sentido similar, véase López, Ulpiano, Lógica de la Justicia, en Revista de Derecho de la Pontificia Universidad Católica del Perú, 21 (1962), pp. 6-7.

${ }^{100}$ Vid. EngmanN, Joyce, cit. (n. 37), pp. 22-24. Este autor recurre al concepto griego de hybris para referirse a las hipótesis de pleonexia que podrían verificarse en las interacciones entre individuos de la nobleza y del pueblo. 
debe reputarse como una "agresión justa"101 determinada en virtud de ciertos principios tendientes a mantener la armonía inherente al orden natural, los cuales, en todo caso, se identifican como consideraciones exógenas a este ${ }^{102}$.

Los aspectos particulares de la justicia en Anaximandro permiten proponer, siguiendo la terminología empleada por M. Ávila Vásquez, una in t e r p r e t a c i ó n pes i m is t a del devenir ${ }^{103}$. Las cosas existentes fuera de lo ilimitado, en tanto se conducen a partir de impulsos pleonéxicos, están destinadas a someterse en algún momento de su existencia a la condena de perecimiento hacia lo ilimitado, poniendo fin a su realidad individual. En este sentido, la destrucción aparece como el sino de fatalidad de todo cuanto existe.

A pesar del carácter desesperanzador que podría atribuirse a esta propuesta interpretativa, es necesario tener presente que el devenir constituye un aspecto esencial en el carácter inmanente de la realidad, toda vez que si la existencia no estuviese determinado por un "destino trágico", sólo hubiese sido posible una instancia generativa única del mundo, permaneciendo este en idéntica trascendencia a lo ilimitado. Por lo tanto, la destrucción de las entidades existentes opera como condición de posibilidad para el surgimiento ininterrumpido de nuevas realidades individuales.

Las cuestiones analizadas en los párrafos precedentes se vinculan, en el marco de la estructura de la justicia punitiva, con la identificación de los sujetos intervinientes (agresor y víctima), de la conducta proscrita, del castigo correspondiente y de los principios que inspiran su imposición. Con todo, los comentarios formulados en torno a la noción de justicia contenida en la sentencia de Anaximandro no se limitan a evidenciar su carácter retributivo, sino que dan cuenta de una naturaleza compleja, en la cual convergen consideraciones de índole restaurativa y distributiva.

La dimensión restaurativa aparece como un complemento necesario de la retribución justa, pues en el procedimiento de determinación del merecimiento de castigo y su aplicación posterior no se considera exclusivamente la magnitud del acto de agresión pleonéxica, sino que también se debe ponderar el daño sufrido por la entidad agredida y el quantum de la reparación necesaria. En consecuencia, el objetivo de la justicia cósmica corresponde a la restauración y resguardo del orden natural y, sólo en aquellos casos en que la agresión supere los límites tolerables o se repute irreparable, debe procederse a la aplicación del perecimiento en lo ilimitado como único mecanismo correctivo adecuado y suficiente.

A su vez, el carácter distributivo de la justicia según Anaximandro se deriva como consecuencia de la racionalidad en que se funda la distribución de los

${ }^{101}$ La lógica subyacente a la noción de "agresión justa” entre opuestos en igualdad de condiciones se asemeja a la forma en que opera la justicia correctiva en la filosofía aristotélica. A este respecto, véase Aristóteles, Ética a Nicómaco (4a reimp., trad. cast. Madrid, Alianza Editorial, 2005), pp. 162-163.

${ }^{102}$ Adhiere a esta afirmación, OppermanN, Jan, cit. (n. 31), pp. 51-54. Este autor fundamenta el carácter externo de los principios que informan la retribución justa en el hecho de que la lógica interna del orden cósmico se sustenta en la existencia del conflicto entre los opuestos y sus tendencias pleonéxicas. A pesar de lo acertado que pudiese parecer este razonamiento, el propio autor lo ha calificado como un "empobrecimiento necesario" de la doctrina de Anaximandro.

${ }^{103}$ Ávila VÁsquez, Manuel, cit. (n. 14), pp. 72-73. 
opuestos en el universo y las dinámicas que rigen sus interacciones recíprocas. En este sentido, al momento de disgregarse los contrarios desde el $\alpha$ $\pi \varepsilon\llcorner\varrho O \nu$, cada uno de ellos ocupa una posición determinada en función del orden natural, es decir, se le asigna "aquello que le corresponde" 104.

En virtud de lo anterior, es posible sostener que todo acto de transgresión implica una ruptura de dicho orden y, en consecuencia, una privación total o parcial de lo que, de acuerdo con la justicia, le corresponde a la víctima. Así, la justicia, incluso en su aplicación correctiva o retributiva, opera como un mecanismo de resguardo o protección de la distribución naturalmente adecuada.

A la luz de lo señalado, adquiere pleno sentido lo afirmado por A. Kaufmann, quien en las líneas finales del fragmento analizado en la sección precedente, sostiene que la conjunción de la "autoafirmación del propio ser" y del deber de "dejar a los otros ser como son" correspondería a un antecedente de la formulación suum cuique, la cual puede traducirse como "a cada uno lo suyo"105.

De este modo, la justicia referida en la sentencia del filósofo milesio debe ser entendida como una noción compleja en la cual se articulan complementariamente cuestiones de índole retributiva, restaurativa y distributiva. Aun cuando no resulte equiparable en cuanto a su nivel de desarrollo y sistematización, el concepto de justicia en Anaximandro podría ser tenido como un antecedente directo de lo expuesto por Aristóteles en el Libro V de la Ética a Nicómaco ${ }^{106}$.

A pesar de la indiscutida relevancia de los tópicos previamente analizados en esta materia, ninguno de ellos permite identificar al sujeto encargado de juzgar los actos de transgresión y, en consecuencia, de dictar la sentencia justa e imponer la condena respectiva.

Según una interpretación sostenida por algunos estudiosos contemporáneos -a la cual se adscribe en el presente artículo-, dicho rol debe ser atribuido al t i e m p o, en razón de lo dispuesto en las líneas finales de la sentencia de Anaximandro, en las cuales se señala que la retribución de la injusticia se debe llevar a

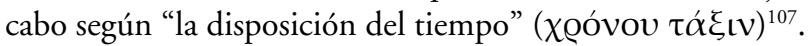

Con todo, la mayoría de los autores que sustentan esta propuesta no se han abocado al estudio detallado de sus aspectos fundamentales, limitándose a identificar sus principales antecedentes en los poemas de Solón -los cuales reconocen la existencia de un "tribunal del Tiempo"108 o el hecho de que la justicia "llega

${ }^{104}$ Los presupuestos básicos a partir de los cuales se estructura la consideración del carácter distributivo de la justicia se sustentan en lo señalado por ARISTÓTELES, cit. (n. 101), pp. 158-160.

${ }^{105}$ Kaufmann, Arthur, cit. (n. 2), p. 52.

${ }^{106}$ Para una exposición general del contenido de dicho Libro de la Ética a Nicómaco, véase García Belaúnde, Domingo, cit. (n. 91), pp. 157-159.

${ }^{107}$ Así, JAEger, Werner, La teología, cit. (n. 4), pp. 40-42; Alabanza de la ley, cit. (n. 1), pp. 23-25; Paideia, cit. (n. 4), pp. 158-159 y Kirk, Geoffrey; Raven, John; Schofield, Malcolm, cit. (n. 8), pp. 181-182. En un sentido diverso, FreudenTHAL, Gad, cit. (n. 51), p. 209, sostiene que el tiempo ha sido incluido en la sentencia de Anaximandro con el objeto de destacar la ocurrencia regular de actos de ejercicio de control, los cuales se someterían a consideraciones independientes de los opuestos.

${ }^{108}$ Cfr. KirK, Geoffrey; Raven, John; SCHOfield, Malcolm, cit. (n. 8), p. 182 (traducción del fragmento $\left.\mathrm{N}^{\circ} 111\right)$. 
a su hora, más pronto o más tarde"109, por lo cual resulta indispensable aportar consideraciones adicionales al respecto.

El tiempo, al igual que todo cuanto existe fuera del $\alpha$ ácเ@ov, proviene de este último, en tanto principio originario. Sin embargo, a diferencia de las demás cosas del mundo, no forma parte de ninguna entidad determinada, sino que trasciende a ellas y las circunda, toda vez que éstas se encuentran sometidas al devenir y cuentan con instantes de nacimiento y destrucción determinables de forma precisa, los cuales forman parte de una progresión temporal de carácter sucesivo.

Por tanto, es posible sostenerse que, de manera similar a la justicia cósmica, el tiempo corresponde a una de las entidades trascendentes en su i n m a n e n c i a, puesto que, con exclusión de lo ilimitado, comprendería, supeditaría y se sobrepondría a todas las cosas existentes, reuniendo características similares al $\not ̋ \pi \varepsilon\llcorner\varrho o v$, pero limitadas a una dimensión circunstancial y perecedera En razón de estas consideraciones, el tiempo aparece como una figura idónea para desempeñar el rol de juez sentenciador, ya que correspondería a un tercero imparcial, desprovisto de intereses y relaciones particulares que pudiesen incidir en la decisión de los conflictos particulares. La imparcialidad aparece como una característica derivada del hecho de que el tiempo corresponde a la única entidad que no cuenta con un opuesto correlativo y, en consecuencia, no se somete a las interacciones agonales o pleonéxicas propias del devenir.

Asimismo, esta propuesta puede sustentarse en un análisis filológico y etimo-

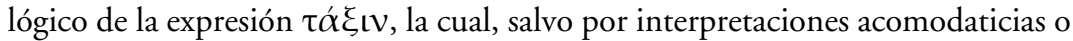
infundadas ${ }^{110}$, suele traducirse como "disposición" u "orden".

Dichas traslaciones deben analizarse a partir del sentido atribuible a los

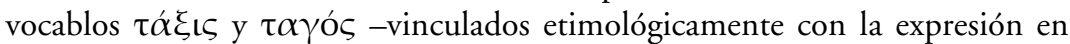
comentario-, los cuales designan, respectivamente, un "arreglo o disposición"111 y un individuo que detenta una posición de liderazgo o mando, especialmente en el ámbito militar ${ }^{112}$. Por lo demás, el sentido natural y obvio de las expresiones "disposición” y "orden" da cuenta de aspectos relacionados con ciertos actos de autoridad $^{113}$, especialmente aquellos asociados a la judicatura o al ejercicio de potestades y atribuciones jurisdiccionales.

De esta manera, el tiempo, a partir de las consideraciones que Anaximandro

${ }^{109}$ JAEGER, Werner, Alabanza de la ley, cit. (n. 1), pp. 23-24.

${ }^{110}$ A modo de ejemplo, véase las traducciones propuestas por ENGMANN, Joyce, cit. (n. 37), p. 3 ("valoración o apreciación") y por H. Diels, según lo señalado en HeIDEGGER, Martin, La sentencia, cit. (n. 7), p. 240 (“fijación”). Sin perjuicio de suscribir a su interpretación en esta materia, es menester señalar que JAEgER, Werner, La teología, cit. (n. 4), pp. 40-41 y Paideia,

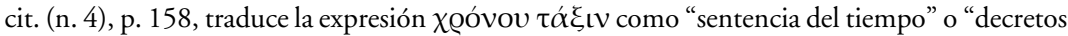
del tiempo", lo cual corresponde, sin duda, a una decisión adoptada con el objeto de validar su tesis interpretativa.

${ }^{111}$ BaIlLy, Anatole, Dictionnaire abrégé grec-fran ais (París, Hachette, 1969), p. 854.

${ }^{112}$ Chantraine, Pierre, Dictionnaire Étymologique de la Langue Grecque (París, Editions Klincksieck, 1977), p. 1088.

${ }^{113}$ En este sentido, el Diccionario de la Lengua Española de la RAE define d i s p o s i c i ó n , en su tercera acepción, como "deliberación, orden y mandato de la autoridad". Asimismo, dicho texto entiende la noción de o r d e n como "colocación de las cosas en el lugar que 
formula en relación con la justicia cósmica, funge como juez o máxima autoridad que, a partir de los principios emanados desde lo ilimitado, impone la condena correspondiente a los opuestos y demás entidades que incurran en transgresiones -cualquiera sea la entidad de estas-, propendiendo a la mantención del orden natural que rige la totalidad del universo.

A modo de síntesis, es posible afirmar que la concepción de justicia en la sentencia de Anaximandro, al igual que las cuestiones analizadas en las secciones precedentes de este acápite, da cuenta de la complejidad y riqueza de su teoría sobre el cosmos, su funcionamiento y los principios que rigen a sus elementos constitutivos y las relaciones de interacción constante entre ellos.

\section{CONCLUSIONes}

Anaximandro de Mileto, según consta en la famosa sentencia transcrita por Simplicio, habría dedicado parte importante de sus reflexiones, al igual que la mayoría de los primeros filósofos griegos, al estudio de asuntos cosmogónicos, cosmológicos y de otras cuestiones vinculadas con el orden y existencia del universo.

Sin perjuicio de las similitudes advertidas con los demás exponentes de la filosofía presocrática, las tesis atribuidas a Anaximandro y las afirmaciones que las componen dan cuenta de que su pensamiento habría alcanzado un estado de desarrollo superior respecto de sus antecesores e, incluso, de algunos de los pensadores que lo sucedieron. Esta afirmación se sustenta en el hecho de que las cuestiones abordadas por el filósofo milesio no cuentan con precedentes directos en la tradición occidental, además de haber sido desarrolladas con un alto nivel de complejidad estilístico y conceptual.

Entre los méritos que deben ser reconocidos al filósofo milesio, además de la demostración de una preocupación particular por la exposición de un sistema coherente y completo en sí mismo, se destaca la diversidad de temáticas abordadas en sus formulaciones teóricas, lo cual incide en que éstas pueden ser objeto de propuestas exegéticas de carácter interdisciplinario.

Dentro de las áreas de conocimiento a partir de las cuales es posible analizar los postulados de Anaximandro se destacan el derecho y la filosofía del derecho, puesto que la sentencia atribuida al filósofo de Mileto se vale de expresiones que pueden ser comprendidas a partir de cuestiones propias de dichas disciplinas y de recursos metafóricos de estilo formulados sobre la base de éstas.

A este respecto, los comentaristas contemporáneos del pensador jónico han enfatizado en ciertos aspectos de la relación existente entre la cosmogonía originada desde lo ilimitado, el orden que gobierna el universo y la teoría de los opuestos, los cuales pueden vincularse con los presupuestos esenciales del derecho natural y sus leyes. En este sentido, puede advertirse la existencia de un orden cósmico establecido a partir del principio originario universal, en virtud del cual se disponen espacio-temporalmente las entidades individuales que integran el cosmos,

les corresponde" (primera acepción) o "mandato que se debe obedecer, observar y ejecutar" (decimoséptima acepción). 
estableciéndose aquello que le corresponde a cada una de ellas por derecho en la composición del mundo, a partir de relaciones de mutua oposición con sus semejantes y del establecimiento de deberes de respeto en favor de los mismos.

Con todo, las individualidades surgidas desde lo ilimitado se comportan según impulsos pleonéxicos, los cuales se concretan en la ocurrencia de transgresiones constantes a los límites existenciales de las demás entidades. En razón de lo anterior, se introduce una noción de justicia cósmica de naturaleza compleja -basada en la confluencia de aspectos de índole retributiva, restaurativa y distributiva-, cuya administración se encomienda al tiempo, en tanto figura imparcial y trascendente en su inmanencia, con el objeto de restituir y asegurar la vigencia efectiva de la lógica organizativa del mundo, lo cual se concreta mediante la imposición de "sanciones" que se extienden desde el deber de soportar transgresiones recíprocas equivalentes hasta el perecimiento definitivo en lo ilimitado.

A partir de las consideraciones expuestas en los acápites precedentes, es dable sostener, en un sentido similar a los autores citados en los párrafos introductorios de este artículo, que los orígenes de la filosofía del derecho pueden remontarse a las cuestiones expuestas en la sentencia de Anaximandro de Mileto. En consecuencia, quedan demostradas la necesidad y utilidad dogmáticas de estudiar los postulados atribuibles a los primeros filósofos griegos, aun cuando esta actividad suponga la exigencia ineludible de superar diversas dificultades asociadas a dicho propósito académico.

BiBLIOGRAFÍA

Aristóteles, Ética a Nicómaco (4a reimp., trad. cast. Madrid, Alianza Editorial, 2005). Asmis, Elizabeth, What is Anaximander's Apeiron?, en Journal of the History of Philosophy, 19/3 (1981), pp. 279-297.

Ávila VÁsquez, Manuel, En torno a la sentencia de Anaximandro. Dos interpretaciones o sobre la justicia y la reparación, en Universitas Philosophica, 28/56 (enero-junio 2011), pp. 61-83.

BAILLY, Anatole, Dictionnaire abrégé grec-fran ais (París, Hachette, 1969).

Bernabé, Alberto, Fragmentos Presocráticos. De Tales a Demócrito (3a ed., Madrid, Alianza Editorial, 2008).

Chantraine, Pierre, Dictionnaire Étymologique de la Langue Grecque (París, Editions Klincksieck, 1977).

Engmann, Joyce, Cosmic Justice in Anaximander, en Phronesis, 36/1 (1991), pp. 1-25. Freudenthal, Gad, The Theory of the Opposites and an Ordered Universe: Physics and Metaphysics in Anaximander, en Phronesis, 31/3 (1986), pp. 197-228.

García Belaúnde, Domingo, La justicia en los orígenes de la filosofía del derecho, en Revista de Derecho de la Pontificia Universidad Católica del Perú, 32 (1974), pp. 138-161.

Giannini, Humberto, Esbozo para una historia de la filosofia ( $3^{a}$ ed., Santiago, Editorial Dionysos, 1979).

GutHrie, William, Los filósofos griegos. De Tales a Aristóteles (2a ed., 7a reimp., 1950, trad. cast. Méjico D.F., Fondo de Cultura Económica, 2010).

Heidegger, Martin, La sentencia de Anaximandro (1946), ahora, en Él Mismo, Caminos de Bosque (1984, trad. cast. Madrid, Alianza Editorial, 2010), pp. 239-277. 
- The Beginning of Western Philosophy. Interpretation of Anaximander and Parmenides (2012, trad. ingl. Indiana, Indiana University Press, 2015).

Hervada Xiberta, Javier, Introducción crítica al derecho natural (11 a ed., Pamplona, Ediciones Universidad de Navarra, 2011).

JAEGER, Werner, La teología de los primeros filósofos griegos (1947, trad. cast. Méjico D.F., Fondo de Cultura Económica, 1952).

- Alabanza de la ley. Los orígenes de la filosofía del derecho y los griegos (2a ed., 1947, trad. cast. Madrid, Centro de Estudios Constitucionales, 1982).

-Paideia: los ideales de la cultura griega (2a ed., 22a reimp., 1933-1945, trad. cast. Méjico D.F., Fondo de Cultura Económica, 2011).

Kaufmann, Arthur, Panorámica histórica de los problemas de la filosofía del derecho, en Kaufmann, Arthur; Hassemer, Winfried; Robles Morchón, Gregorio (a cura di), El pensamiento jurídico contemporáneo (Madrid, Editorial Debate, 1992), pp. 47-141.

KaHN, Charles, Anaximander and the Origins of Greek Cosmology (New York, Columbia University Press, 1960).

Kirk, Geoffrey; Raven, John; Schofield, Malcolm, Los filósofos presocráticos. Historia crítica con selección de textos ( $2^{\mathrm{a}}$ ed., $2^{\mathrm{a}}$ reimp., 1983, trad. cast. Madrid, Editorial Gredos, 1987).

López, Ulpiano, Lógica de la justicia, en Revista de Derecho de la Pontificia Universidad Católica del Perú, 21 (1962), pp. 5-15.

NiETzSCHE, Friedrich, Los filósofos preplatónicos (1913, trad. cast. Madrid, Editorial Trotta, 2003).

Oppermann, Jan, Anaximander's Rhythm and the Question of Justice, en Law and Critique, 14/1 (2003), pp. 45-69.

Pacheco Gómez, Máximo, Teoría del derecho (4a ed., Santiago, Editorial Jurídica de Chile, 1990).

Seaford, Richard, Money and the Early Greek Mind. Homer, Philosophy, Tragedy (Cambridge, Cambridge University Press, 2004).

Vlastos, Gregory, Equality and Justice in Early Greek Cosmologies, en Classical Philology, 42/3 (1947), pp. 156-178. 